\begin{tabular}{|c|c|c|c|c|c|}
\hline MUNIBE Antropologia-Arkeologia & $n^{\circ} 65$ & $117-136$ & DONOSTIA & 2014 & ISSN 1132-2217 • eISSN 2172-4555 \\
\hline
\end{tabular}

\title{
Enterramientos de la Edad del Bronce en la Meseta Sur peninsular a partir del Sector 22, Yuncos (Toledo)
}

\author{
Bronze Age burials in the southern Iberian Meseta \\ from Sector 22, Yuncos (Toledo)
}

KEY WORDS: Iberian Peninsula, Tagus basin, Cogotas I Culture; burials pits.

PALABRAS CLAVES: Península Ibérica, Cuenca del Tajo, Cogotas I, enterramientos en hoyo. GAKO-HITZAK: Iberiar penintsula, Tajo arroa, Cogotas I, hobian lurperatzea.

\section{Rosa BARROSO(1), Primitiva BUENO(1), Armando GONZÁLEZ(2), Nieves CANDELAS ${ }^{(2)}$, Juan Manuel ROJAS(3) y Jose Antonio LÓPEZ SÁEZ(4)}

\begin{abstract}
The results of the analyses of two tombs from the Sector 22 site in Toledo are presented in this article. The four buried individuals from this site display some of the most unique aspects found in Cogotas burials from the Meseta, like the young age of the deceased, infants and juveniles, the association of primary and secondary burials in the same tomb, the presence of ceramic gravegoods and a considerable animal offering. The designation of these burials to the Cogotas I culture has been confirmed by a C-14 dating.

The burials are situated within the group of Cogotas burials in the Tagus basin, contrasting the data with the Northern Meseta. The main topics that are analyzed are the chronology, funerary manners, population, pathological signs and spatial positioning of the tombs. The number of burials that have been found in the Southern Meseta up until now is small and there are few absolute datings. Compared with the previous Chalcolithic there is a considerable decrease in the number of burials and the variety of structures, now reduced to pits. Among the many variables in the deposition of the deceased and the applied ritual, the use of this type of tombs is an essential common element. The presence of juvenile individuals stands out in the buried population, but in order to determine the selection of an age group a broader sample would be necessary. However, we can confirm that the age and sex of the individuals do not determine a specific type of burial. Finally, a habitat-tombs analysis is not possible in spite of their overlapping in the terrain as the settlements are only partially known. They lack a structural, archaeological or topographical delimitation. Beyond their grouping in certain areas no clear common criteria regarding the location of the burials are evident so far.
\end{abstract}

\section{RESUMEN}

Presentamos los resultados del análisis de dos tumbas del yacimiento del Sector 22 en Toledo. Sus cuatro individuos reúnen algunos de los aspectos más singulares de los enterramientos Cogotas I de la Meseta, y una fecha C-14 que asegura su adscripción. Las sepulturas se encuadran posteriormente en el conjunto de enterramientos Cogotas que conocemos hoy en el Tajo, valorando y contrastando con la Meseta Norte, cuestiones que atañen a la cronología, los modos funerarios, la población enterrada y la localización espacial de las tumbas.

\section{LABURPENA}

Toledoko 22. Sektoreko aztarnategiko bi hilobitako analisien emaitzak aurkezten ditugu. Lau pertsona dira. Goi-ordokiko I Cogotas lurperatzeen alderdirik berezienetako batzuk dituzte, eta C-14 datak haien adskripzioa bermatzen du. Hilobiak gero gaur egun Tajon ezagutzen dugun Cogotas lurperatzeen multzoan sartzen dira, eta Iparreko Goi-ordokiarekin baloratu eta kontrastatzen dira kronologiari, ehorzteko moduei, lurperatutako populazioari eta hilobien kokapen espazialari buruzko alderdiak.

\section{1.- INTRODUCCIÓN}

Las prácticas funerarias en la Meseta Sur, cuenca del Tajo, han sido nuestro objeto de estudio en los últimos años. Buena parte de nuestros trabajos se han centrado en los yacimientos excavados en el Valle de Huecas (To- ledo): El Castillejo y la necrópolis de hipogeos de Valle de las Higueras, mayoritariamente situados entre Neolítico Calcolítico (BUENO et al. 2009), si bien el uso funerario y habitacional del valle se prolonga hasta bien avanzada la Edad del Bronce (BUENO et al. 2000).

\footnotetext{
(1) Área de Prehistoria. Facultad de Filosofía y Letras. Universidad de Alcalá. C/ Colegios 2, 28801, Alcalá de Henares, Madrid; rosa.barroso@uah.es; p.bueno@uah.es

(2) Laboratorio de Poblaciones del Pasado. Departamento de Biología. Facultad de Ciencias. Universidad Autónoma de Madrid. armando.gonzalez@uam.es; mnieves.candelas@titulado.uam.es

(3) Juan Manuel Rojas arqueología S.L.; jmrojasrodriguez@yahoo.es

(4) Grupo de Investigación Arqueobiología. Instituto de Historia, CCHS, Madrid; joseantonio.lopez@cchsih.csic.es 
El yacimiento del Sector 22 que ahora nos ocupa, también se localiza en Toledo, en el municipio de Yuncos, y nos ha permitido seguir profundizando en los comportamientos funerarios de la Edad del Bronce en el Tajo. Su situación al pie de la necrópolis de cuevas artificiales de Valladares (RUIZ, 1975), duplica una topografía similar a la de Huecas y reproduce registros semejantes: enterramientos en altura excavados en la roca y una ocupación del valle. Recogemos aquí el estudio de las sepulturas localizadas en estas tierras bajas, de las que dimos escueta noticia (BARROSO et al. 2011), ligadas a grupos Cogotas I de escasa documentación en la zona.

Para dar contexto a estos hallazgos examinamos los enterramientos Cogotas de la Meseta Sur y abordamos algunos de los aspectos más destacados de esta población enterrada. A partir de trabajos anteriores que han tratado el tema (ESPARZA, 1990; BLASCO et al. 1991a; MONTERO, 2011) reunimos un inventario de enterramientos que, sin ser total, cubre el propósito de partida. Igualmente nos valemos de los últimos avances del proyecto de investigación que sobre Cogotas en la Meseta Norte realiza el equipo dirigido por A. Esparza (ESPARZA et al. 2012a). Su trabajo, centrado en los enterramientos en hoyos, los únicos conocidos en el Tajo, nos ofrece un excelente marco de comparación y actualización de la información meridional.
Un registro reducido, como el que veremos que caracteriza a Cogotas I, o minoritario y excepcional, como se ha planteado defendiendo prácticas normativas sin huella arqueológica como la exposición de los cadáveres a la intemperie (ESPARZA et al. 2012b:119) podría desalentar cualquier estudio como el que pretendemos exponer en estas páginas. Sin embargo, el registro funerario es significante (VICENT, 1995), y, como tal, revelador de prácticas de naturaleza variable que siempre es importante analizar. Estamos ante algunos de los pocos "restos" en posición primaria que encontramos en los poblados de hoyos.

\section{2.- LAS TUMBAS DESECTOR22, YUNCOS(TOLEDO)}

\subsection{El yacimiento}

El yacimiento responde al enclave característico de Cogotas I en la Meseta, un asentamiento de fondos de cabaña. Ocupa una suave ladera de tierra de uso agrícola, entre dos arroyos próximos, y es colindante con un tramo de antigua cañada entre Bargas y Toledo. Geológicamente dominan los depósitos terciarios, mayoritariamente de arcillas con arenas de grano fino intercaladas.

La carta arqueológica del término de Yuncos muestra veintiún yacimientos en el entorno del Sector 22, que abarcan desde el Calcolítico hasta época romana (Fig. 1). Su

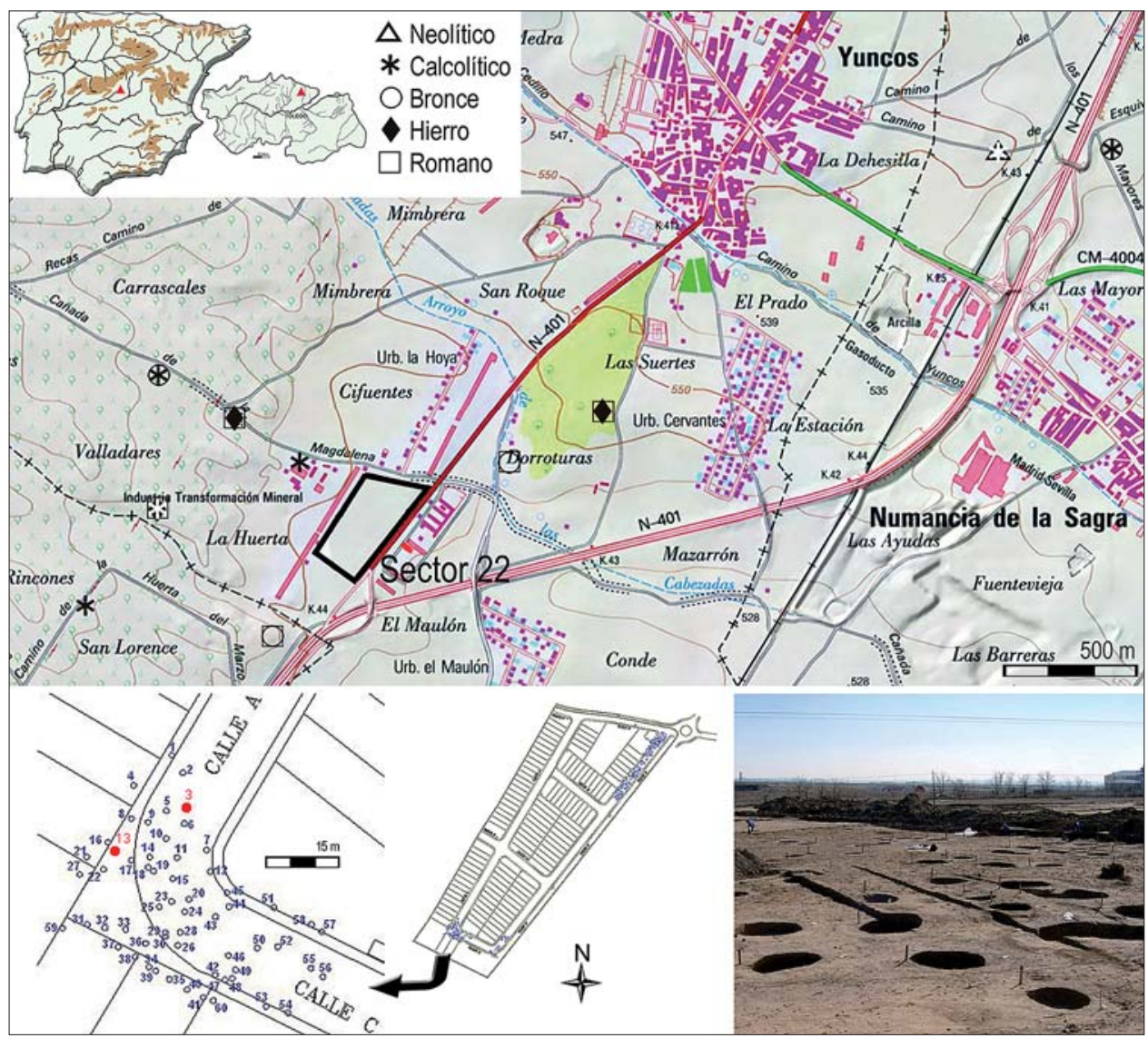

Fig. 1. Localización del Sector 22 (Yuncos) y los yacimientos de su entorno. Abajo, fotografía de la excavación y planimetría del yacimiento con detalle del área suroeste y los dos fondos funerarios. / Location of Sector 22 (Yuncos) and distribution map of other known archaeological sites. Below, view of the excavation, settlement plan and detail of the Southwest area with the funerary structures. 
concentración y prolongación hacia los vecinos términos de Yuncler y Numancia de la Sagra, con yacimientos como La Paleta y Las Mayores, que reunirían un millar de estructuras remontándose incluso hasta Neolítico (PERERA et al. 2010), nos sitúa en un espacio de intensa ocupación prehistórica. De ellos destacaremos, a sólo $3 \mathrm{Km}$, El Sector 25 - El Cerrón. Su excavación localizó más de un centenar de estructuras Cogotas I (MARTIN, 2010). El éxito de las comunidades agropecuarias en la zona y su forma de vida en poblados amplios y abiertos de silos, como el que nos ocupa, es evidente.

El paisaje actual que rodea el yacimiento está desvirtuado por los desmontes para la instalación de una fábrica de arcilla a finales de los 60. La construcción de un polígono industrial motivó su excavación en 2005, por la empresa de J.M. Rojas, el único firmante que participó en los trabajos arqueológicos. De los $98.964 \mathrm{~m}^{2}$ que tiene la parcela, se abrieron solo las calles $(2 \mathrm{H})$ afectadas por la construcción, lo que nos impide determinar la extensión real del yacimiento formado por dos áreas, noreste y suroeste, 2430 y $2100 \mathrm{~m}^{2}$, respectivamente, con 130 y 98 estructuras. 300 $\mathrm{m}$ separan ambas, quedando una zona central deprimida y con posibilidad de inundaciones por escorrentía.

Todas las estructuras entrarían en la definición de silos (DÍAZ DEL RIO, 2001: 141), sin documentarse cabañas. Sus características son variadas y compartidas en ambas áreas, salvo los fondos utilizados como tumbas (fondo 13A y 3), sólo al suroeste.

En la adscripción del yacimiento contamos con una fecha de la plenitud de Cogotas I procedente de uno de los enterramientos y abundante cerámica decorada característica del grupo por todo el yacimiento. No faltan los esquemas sencillos característicos de la etapa inicial, pero tampoco el boquique, la excisión o los motivos y morfologías avanzadas, quizás en la línea de una ocupación dilatada.

Para ratificar la existencia de un paisaje frecuentado y antropizado, realizamos análisis polínicos de 11 muestras de tierra preservada durante la excavación, incluyendo varias de la secuencia estratigráfica del fondo 3. Sólo una, localizada bajo el enterramiento (UE7), resultó estadísticamente significativa. Los resultados muestran un paisaje enormemente deforestado. Los árboles no llegan al $13 \%$ incluyendo Pinus sylvestris tipo (8\%), cuya presencia es alóctona. El bosque climácico sólo está representado por un $5 \%$ de encina (Quercus ilex) y un $1 \%$ de enebro (Juniperus). La cobertura arbustiva es del 14\%, y en ella predominan jaras (Cistus), brezos (Erica arborea tipo), acebuche (Olea) y espino majuelo (Crataegus), todos ellos con un 3\%; y en menor medida Phillyrea y labiadas. La cobertura herbácea es mayoritaria (73\%), dominando planicies pobladas de gramíneas (36\%) y numerosas zonas de pastizal tanto de origen antrópico, fuertemente nitrificados, como antropozoógeno. En definitiva, hay notoria presencia humana en el medio, especialmente determinada por una ingente presión pastoral, también constatada por hongos coprófilos como Sordaria sp. (2\%).

Este paisaje antropizado se atestigua en otros registros paralelos de la zona como El Caserío de Perales (Getafe) (RUIZ et al. 1997). En sus polínicos había leguminosas, además de cultivos de trigo y cebada ratificados sólo mediante carpología (RUIZ et al. 1997: 162). En la muestra polínica del Sector 22 no hay evidencia de cereal aunque sí un $6 \%$ de leguminosas, sin poder determinarse como especie cultivada o no. El resto de muestras no resultaron estadísticamente significativas. Sin embargo, en la mayoría de ellas abundaron esporas de hongos pirófilos indicativos del uso del fuego (Chaetomium sp.), e incluso (fondo 4 y 16) algún polen de cereal. Una agricultura de cereal y regadío como la del poblado madrileño, junto a la ganadería, es igual de factible en Sector 22.

\subsection{Las estructuras funerarias y su contenido}

Los enterramientos, cuatro en total, se localizan en dos fondos (13A y 3 ) del área suroeste. Ambos difieren en su forma y dimensiones, pero con una variabilidad integrada perfectamente en la heterogeneidad del resto de las estructuras del yacimiento. No hay una tipología específica de hoyos-tumba y, al menos en el fondo 3, podemos rechazar su apertura ex profeso para el gesto funerario. Su nivel inferior (UE7) con mínimos fragmentos de cerámica quemada y carbones podría estar indicando la higienización del silo y un posterior abandono (UE6) previo a su uso para el triple enterramiento. La muestra de polen procedente de ese nivel basal (UE7), presenta abundantes ascosporas de hongos carbonícolas (Chaetomium sp, $12 \%$ ) que constatan el uso del fuego. La presencia de materiales residuales, deja abierta la posibilidad de diversas acciones de manipulación, uso o preparación de la estructura, previas al enterramiento.

En el fondo 13A (Fig. 2), su único enterramiento se situó directamente en la base. De su uso originariamente funerario sería esperable que su relleno careciera de desechos alimenticios o materiales, pero no sólo no es así sino que la estructura corta otros dos fondos previos. De esta forma, adopta una planta final trilobulada y desde luego una conexión con depósitos anteriores que parece intencionada. Su interior acogió lateralmente un enterramiento y un recipiente liso, boca abajo, junto a su cabeza. Ni con este elemento se ocupa la zona central de la estructura que queda libre.

El cuerpo también se colocó boca abajo y fuertemente flexionado a modo de auténtico paquete óseo. Se trata de un individuo de sexo indeterminado, una edad estimada de 10 años $( \pm 2,5)^{1}$ y una estatura de $1,35 \mathrm{~m}$. Como caracteres

1En los individuos analizados se ha utilizado el método de estimación de la edad a partir de la erupción y calcificación dental propuesto por UBELAKER (1978). La estatura se calcula a partir de las ecuaciones de regresión propuestas por VIRTAMA et al. (1962). 


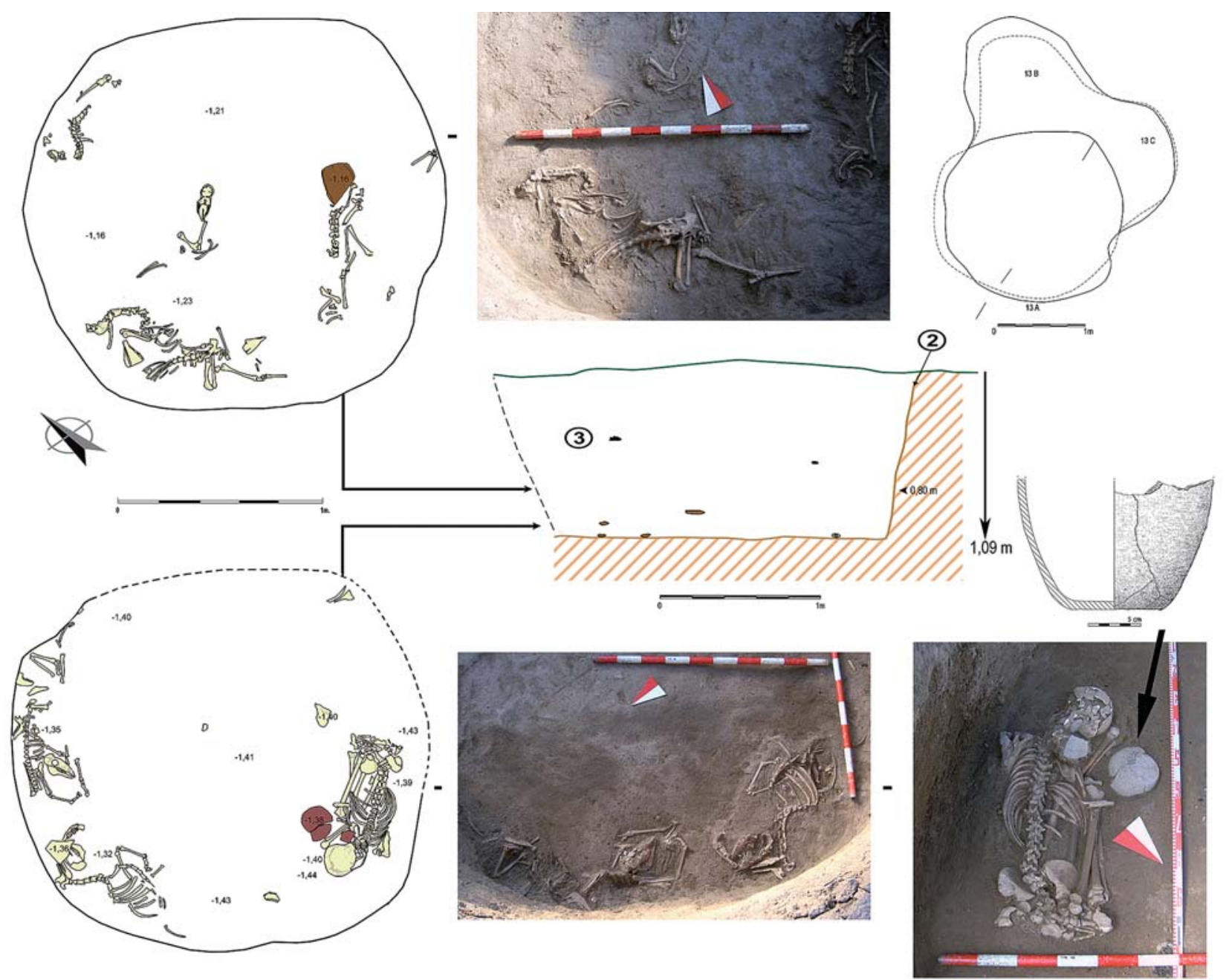

Fig. 2. Enterramiento 13A del Sector 22: Planta y sección con fotografías y dibujos de su excavación, así como dibujo del recipiente que formaba parte del ajuar. / $13 \mathrm{~A}$ Sector 22 burial: view and section of the pit with photos, drawing of excavation and grave goods.

de interés hay que señalar que aún conservaba piezas de leche con marcada atrición pero sin caries, y cribra femoral (POLO, 2000) bilateral. Como caracteres patológicos se observó hipoplasia del esmalte en los incisivos superiores.

El fondo 3 (Fig. 3) cuenta con distintos niveles estratigráficos, destacando un nivel muy reducido (UE5) que agrupa tres enterramientos, dos secundarios y un primario. Quizás la posible incorporación de algún enterramiento más, mantiene la estructura abierta algún tiempo, cayendo material rubefactado de sus paredes (UE4) para finalmente colmatarse con sedimento que incluye abundantes restos (UE3).

En la zona inferior se localizó un individuo sin conexión anatómica (Individuo 3) con los restos óseos esparcidos por la mitad este del fondo. Podría pensarse en su esqueletización y posterior desplazamiento, abriendo espacio en la estructura, pero el análisis antropológico muestra la falta casi completa de pies y manos, las rótulas o varias vértebras, por ejemplo las cervicales completamente ausentes, en definitiva, el carácter secundario del enterramiento: un individuo infantil de 9 años ( \pm 24 meses). Su dentición muestra fuerte atrición de los dientes de leche, escasas piezas afectadas por caries y depósitos de cálculo en la parte anterior de la mandíbula. Los restos humanos se entremezclaban con algunos huesos de fauna.

Al margen de cierto desorden de huesos desarticulados, el enterramiento se "ordena" por cuanto la mandíbula inferior, con todos los dientes en el momento de su hallazgo, fue colocada junto al cráneo de otro individuo (Individuo 2), situado en el borde sur del hoyo y que en nuestro trabajo previo creímos compatible (BARROSO et al. 2011). Ahora podemos asegurar que de este segundo enterramiento, un individuo infantil de 4 años ( \pm 12 meses), solo se depositó su cráneo.

Inmediatamente encima de ellos, y en el mismo lado del Individuo 3 se realizó un tercer enterramiento (Individuo 1) que repite similar situación periférica dentro de la estructura que el enterramiento 13A. Estaba en conexión anatómica, boca arriba, con las extremidades flexionadas, los 


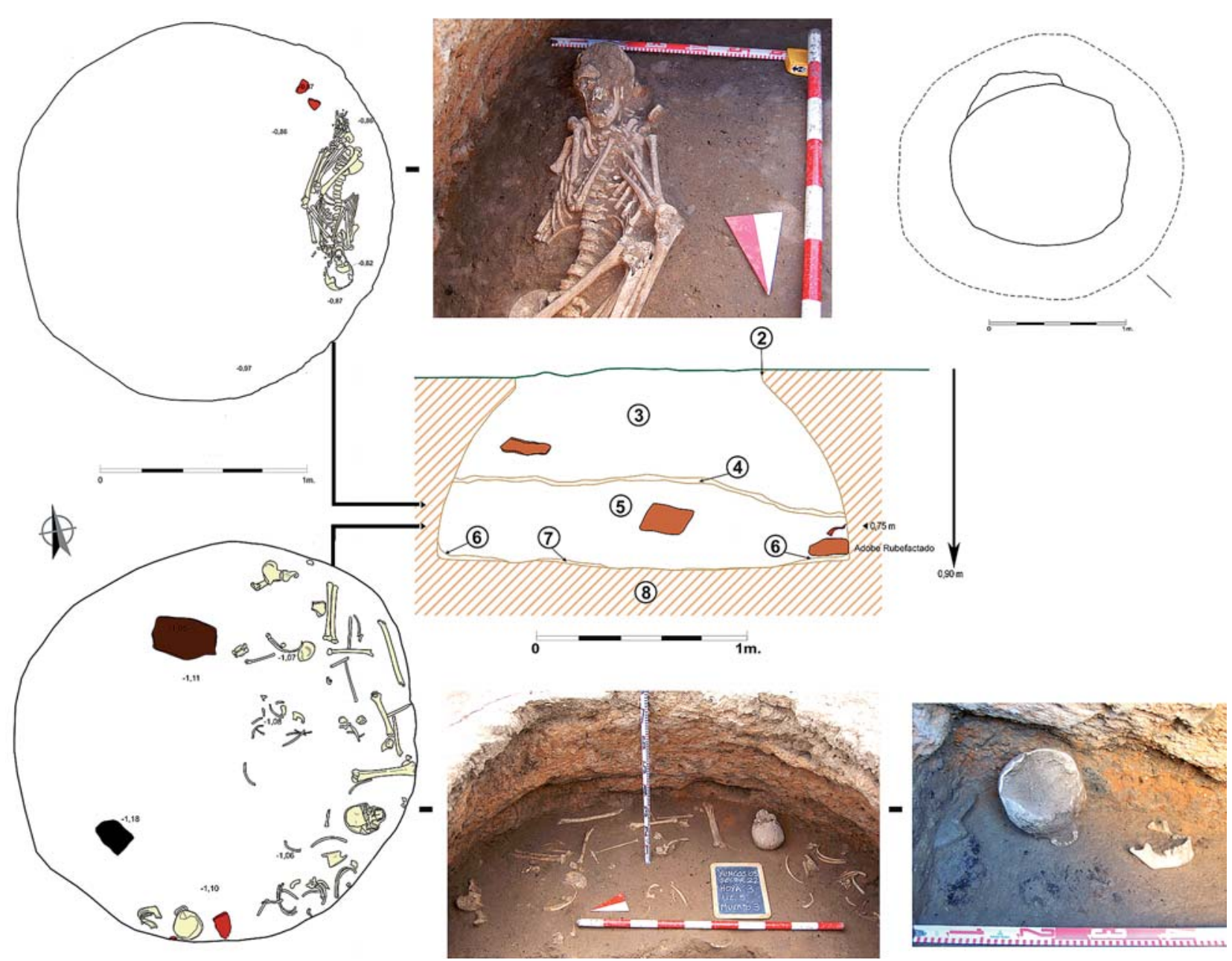

Fig. 3. Planta y sección del fondo 3 del Sector 22, con fotografías y dibujos de su excavación. / 3 Sector 22 burial: View and section of the pit with photos and drawing of excavation.

brazos sobre el torso y las piernas giradas hacia su lado izquierdo. Tiene una edad estimada de 10 años $( \pm 2.5)$ y una estatura de 1,25 m. Los únicos caracteres patológicos observados fueron la presencia de líneas de hipoplasia dental, más evidentes en los incisivos inferiores y caries en los molares de leche superiores, ya muy desgastados.

Los restos faunísticos ${ }^{2}$ de ambos fondos mostraban una buena preservación, escasa fragmentación y buenas superficies óseas. Del total, 778 restos, casi el 90\%, corresponde al fondo 13A. Sus valores pueden estar sobredimensionados, pues la estructura cortaba otros dos anteriores y eso supone cierta imprecisión en la determinación de los niveles superiores, pero no hay ninguna duda de la existencia en él de un elevado porcentaje de fauna determinable con predominio de los ovicaprinos en conexión anatómica. Estos son también los animales más repre- sentados en el fondo 3 aun cuando más de la mitad de los restos no pudieron adscribirse taxonómicamente. (Tabla 1)

\begin{tabular}{|c|c|c|c|c|c|c|c|c|c|c|}
\hline \multicolumn{3}{|c|}{ Fondo 3} & NMI & & & \multicolumn{2}{|c|}{ Fondo 13A } & NMI & & \\
\hline Taxón & NR & Infantl & Juvenil & Adulb & Total & NR & Infant & Juvenil & Adulb & Total \\
\hline Bos taurus & 2 & 0 & 0 & 1 & 1 & 48 & 1 & 1 & 1 & 3 \\
\hline Equus caballus & 2 & 0 & 0 & 1 & 1 & 0 & 0 & 0 & 0 & 0 \\
\hline Cervus elaphus & 0 & 0 & 0 & 0 & 0 & 1 & 0 & 0 & 1 & 1 \\
\hline Ovis aries/Capra hircus & 22 & 1 & 0 & 1 & 2 & 250 & 1 & 1 & 2 & 4 \\
\hline Ovis aries & 5 & 0 & 0 & 1 & 1 & 309 & 2 & 3 & 2 & 7 \\
\hline Sus domesticus & 0 & 0 & 0 & 0 & 0 & 1 & 0 & 1 & 0 & 1 \\
\hline Canis familiaris & 1 & 0 & 0 & 1 & 1 & 9 & 0 & 1 & 0 & 1 \\
\hline Lagomorí & 2 & 0 & 0 & 1 & 1 & 1 & 0 & 1 & 1 & 2 \\
\hline Indeterminado & 59 & & & & & 66 & & & & \\
\hline TOTAL & 93 & & & & 7 & 685 & & & & 19 \\
\hline
\end{tabular}

Tabla 1: Restos de fauna de los fondos funerarios (3 y $13 \mathrm{~A}$ ) del Sector 22 Table 1: Faunal remains from funerary pits ( 3 and 13A) of Sector 22.

²El estudio arqueozoológico ha sido realizado por Verónica Estaca y José Yravedra (2011). Para la identificación taxonómica, cálculo de NR, la adscripción del NMI, la observación de los patrones de edad y el cálculo de edades se utilizaron los mismos criterios y obras referencia de otros estudios anteriores (YRAVEDRA y ESTACA, 2013: 173-174). 
El análisis faunístico se limita a los fondos funerarios, pero el elenco de especies resultante es el atribuido a Cogotas I (ABARQUERO, 2005: 50; BLASCO, 2004: 374) por lo que podría representar la cabaña característica del yacimiento en la que predominarían ovicaprinos seguidos de vacuno. Otra cuestión diferente es el patrón de sacrificio obtenido: anímales muy jóvenes, incluso en el caso de los consumidos como el vacuno. En este caso podría existir sesgo por la funcionalidad funeraria de las estructuras.

La singularidad del fondo $13 \mathrm{~A}$ reside en la edad infantil y juvenil de más de la mitad de los animales consumidos o sacrificados, especialmente ovicaprinos y vacuno, así como de depósitos en conexión anatómica que no excluyen los restos, presumiblemente alimenticios, en el relleno. A unos $80 \mathrm{~cm}$ de la boca se localizaron tres individuos, Ovis aries, y dos más incompletos con porciones axiales y craneales. Corresponden a dos adultos, dos juveniles y un infantil dispuestos en buena parte del borde de la estructura, con tramos que alcanzan la zona central. Previamente se depositaron otros cuatro más, dos de ellos completos. Se concentraban en el borde noroeste del fondo, continuación del enterramiento ya descrito, dejando el centro de la estructura libre. Corresponden a dos ovicaprinos adultos y dos más identificados como Ovis aries, un juvenil y un infantil.

Para contrastar esta abundante ofrenda cárnica con la alimentación de los enterrados, realizamos análisis de paleodieta $^{3}$. Los resultados muestran una dieta vegetal basada en productos ricos en magnesio, vegetales verdes, cereales, legumbres, fruta y abundantes frutos secos. Hay una ingesta pobre de carne roja (niveles Zn/Ca por debajo de 0.35), no toman habitualmente pescado, crustáceos o moluscos, pero sí leche o derivados, dado sus elevados niveles de Vanadio, lo cual podría estar en relación con la corta edad de todos los enterrados. El patrón alimenticio resulta semejante al de otros enterramientos próximos de la Meseta Norte analizados mediante elementos traza (FABIÁN y BLANCO, 2011:186), pero contrasta con los resultados preliminares obtenidos a partir de isótopos estables que apuntan a una dieta proteica de carne (ESPARZA et al. 2012a: 306).

En ambos fondos hay abundantes fragmentos cerámicos sin posibilidad de ensamble, si bien algunos aparentan ser del mismo recipiente. La excepción es el mencionado recipiente colocado junto al individuo del hoyo 13A. Es un recipiente hondo, globular, con base plana al que le faltaba el borde superior. Sus superficies fueron meramente alisadas y presentaba al interior una fuerte concreción amarillenta que junto a su posición boca abajo plantea su servicio más por su contenido que por la pieza en sí. Su posición protege el interior del sedimento de relleno de la fosa y al eliminar su borde se rebaja su altura, no destacando por encima del individuo junto al que se colocó. Los recipientes enteros y boca abajo en determinados hoyos se han interpretado como piezas en espera de almacenar grano (BLASCO, 2012: 213), pero podrían ser contenedores de comida elaborada puesto que se asocian a depósitos de fauna (BARROSO, 2002: 77).

Desde que se individualiza claramente la estructura, encontramos 80 fragmentos cerámicos (2273 gr.) de los que sólo uno está decorado. En definitiva, un material poco diagnóstico sólo con un contexto claro a partir de la fecha C-14 realizada sobre un fragmento del peroné izquierdo del enterrado. Su resultado Beta 364013: $3070 \pm 40 B P$ remite, como poco, a comienzos de la plenitud Cogotas.

El fondo 3, con 3117 I de capacidad, contenía 408 fragmentos cerámicos (5749 gr), varios restos de talla de sílex y un diente de hoz. Predomina la cerámica lisa, frente a la decorada $(4,41 \%)$ y su repartición por toda estructura es desigual, concentrándose hacia la base, en la unidad estratigráfica que incorpora los enterramientos (77,2 \%). Recogemos gráficamente decoraciones y formas más significativas (Fig. 4), señalando la ausencia de boquique y excisión. El evento funerario triple podría tener una cronología similar a la del fondo 13A.

\section{3.- ENTERRAMIENTOS COGOTAS I EN LA ME- SETA SUR. UN CONTEXTO PARA EL SECTOR 22}

\subsection{Lo que conocemos}

Los hallazgos funerarios de la Meseta Sur se señalan como abundantes en proporción a los contextos conocidos (ABARQUERO, 2005: 101) y han aumentado notablemente desde el primer estudio de los 90 (ESPARZA, 1990). Se ha asentado la idea de una presencia constante pero puntual (BLANCO et al. 2007: 59) especialmente relevante en los poblados Protocogotas y mucho más reducida durante la fase plena de Cogotas I.

Reunimos 47 tumbas $(\mathrm{NMI}=57)$ adscritas a Cogotas. Proceden de 16 intervenciones en poblados abiertos, campos de hoyos, localizados tanto en altura como en zonas bajas, y excavados en distinta extensión y circunstancias. A ellos habrá que sumar varios aún pendientes de análisis como Humanejos (RíOS, 2011a: 269-270), por citar sólo alguno (Tabla II). Son escasos para la población del momento pero su cuantía muestra otras cuestiones a destacar.

La primera es que los hallazgos se han realizados fuera de todo proyecto de investigación y dentro de las necesidades constructivas que han conducido la mayor parte de la arqueología de los últimos años tanto en la Meseta Norte (ESPARZA et al. 2012a: 263) como en la Sur. Es decir, pueden calificarse de fortuitos. Sin embargo, dada la falta de búsqueda planificada hacia un determinado ámbito o etapa cultural, resulta significativa la distinta imagen patente hoy en la Meseta Sur entre el conjunto funerario cal-

\footnotetext{
${ }^{3}$ El análisis ha sido realizado por G. Trancho y B. Robledo de la Facultad de Ciencias Biológicas de la Universidad Complutense de Madrid. Los principios básicos de la técnica que permite evaluar el tipo de dieta según la concentración de oligoelementos presentes en el hueso, han sido expuestos en trabajos anteriores (TRANCHO et al. 2004).
} 


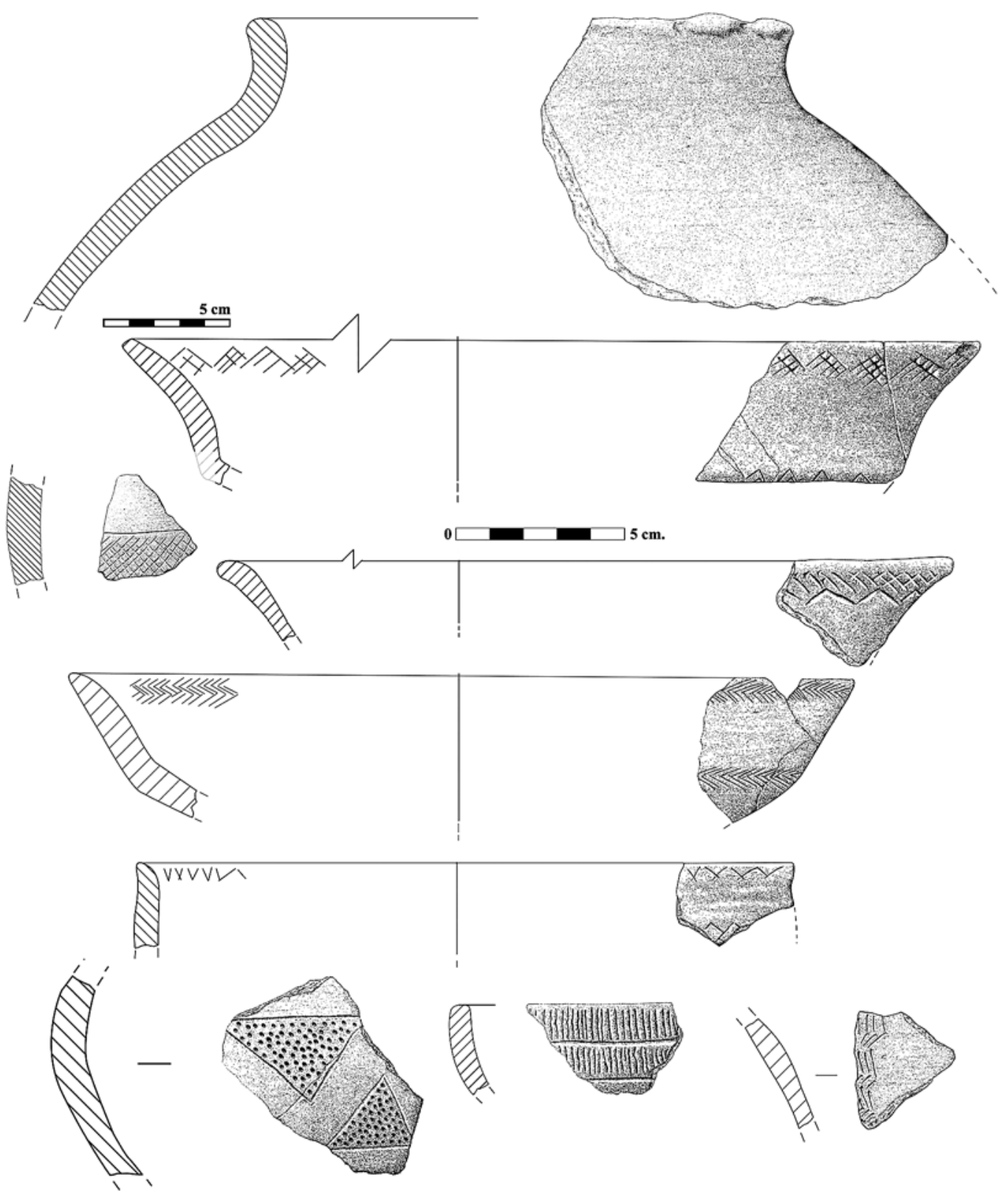

Fig. 4. Restos cerámicos del fondo 3 (dibujos de A. Vázquez). / Pottery found in the pit 3 (drawing by $A$. Vázquez). colítico y el de la Edad del Bronce, éste con evidente menor presencia que aquel. Varios yacimientos calcolíticos excavados en los últimos años han proporcionado necrópolis como agrupaciones numerosas. Es el caso de los 64 enterramientos de Camino de las Yeseras (BLASCO et al. 2009: 42), los 24 de Humanejos (FLORES, 2011: 16).

Una segunda cuestión, igual de casual, queda patente en el hallazgo del yacimiento de Los Berrocales (ALIAGA y MEGÍAS, 2011) que cambia de golpe esa idea de la reducida agrupación de enterramientos de la Edad del Bronce. Sus 48 enterramientos, entre Bronce Antiguo y Medio, son el conjunto más importante del II milenio a.C. que conocemos hoy en el Tajo interior, superando los 23 enterramientos de la Loma del Lomo (VALIENTE, 1992), o los del Castillo de Bayuela (GIL et al. 1988). Sus 13 ente- rramientos adscritos a Cogotas I, quizás más, pues otras tantos carecen de fechas o material distintivo (ALIAGA y MEGÍAS, 2011: 89-91), nos sitúa en agrupaciones que duplican, como poco, los siete enterramientos de El Caserío de Perales, hasta el ahora el más numeroso. El tamaño de las agrupaciones de enterramientos Cogotas y los criterios que las rigen parecen aún abiertos a una cierta provisionalidad en el ámbito del Tajo.

\subsection{La escasez cronológica}

La falta de fechas afecta de lleno a Cogotas I en la Meseta Sur. Contamos con nueve fechas radiocarbónicas sobre hueso, todas ellas en Madrid a excepción de la obtenida en el Sector 22 de Yuncos. Hay una más de La Fá- 


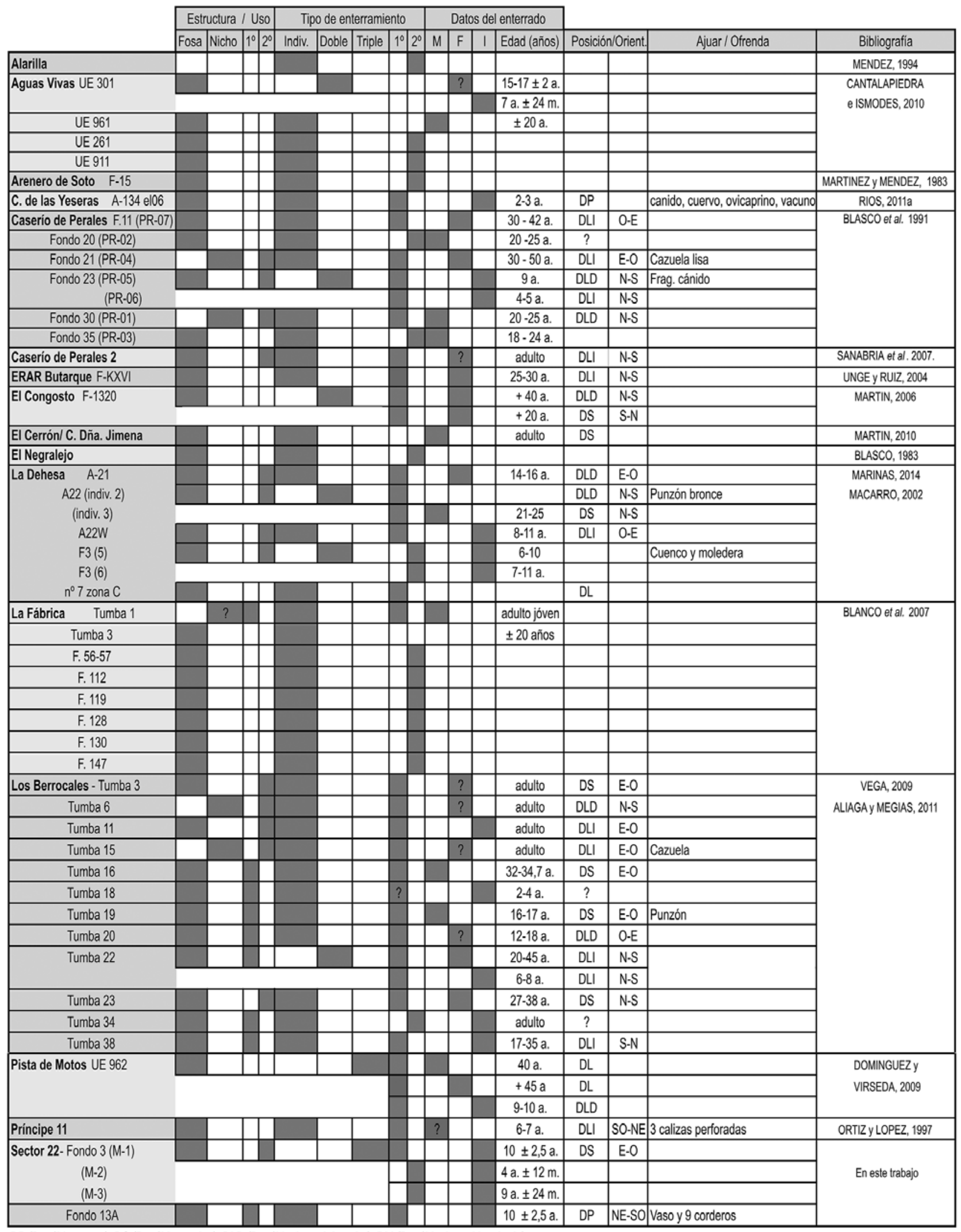

DP (Decúbito prono); DS (Decúbito supino); DLD (Decúbito lateral derecho); DLI (Decúbito lateral izquierdo).

Tabla 2: Inventario de enterramientos Cogotas I de la Meseta Sur.

Table 2: List of Cogotas I burials in the Southern Iberian Meseta. 
brica de Ladrillos (Getafe, Madrid), realizada mediante TL sobre cerámica, aunque con amplia desviación (BLASCO, 2007a: 200).

La situación dentro del yacimiento y la tipología material han primado a la hora de determinar la cronología. Recordemos que la fecha obtenida en El Caserío de Perales a partir de un hueso de fauna del fondo 13 (CSIC-1089: $3356 \pm 68$ BP) (BLASCO et al. 1995), sin registro funerario, fue durante mucho tiempo la única que garantizaba la proximidad cronológica entre los contextos del norte y sur de la Meseta en relación a los primeros momentos de Cogotas. La vinculación de los siete enterramientos localizados en el yacimiento a Protocogotas se realizó a partir de las cerámicas que contenían sus estructuras o, como en el caso de los enterramientos 11, 20 y 21, por la proximidad de las tumbas a otras estructuras con materiales significativos de la etapa (BLASCO et al. 1991a: 61 y 63). Tampoco faltan ejemplos recientes. En el yacimiento de Aguas Vivas la fecha obtenida sobre carbón en uno de sus fondos CIRCE 498: 3303 $\pm 21 \mathrm{BP}$ se hace extensible al sector 1 (CANTALAPIEDRA e ISMODES, 2010: 163) en el que se localizan los enterramientos.

Las fechas absolutas (Fig. 5) sitúan los enterramientos conocidos en la Meseta Sur en el mismo rango cronológico (1881-1010 cal BC) que en la Meseta Norte (ESPARZA et al. 2012a: 268) donde también el número de fechas de la plenitud de Cogotas es más reducido. En el Tajo sólo el fondo 13A del Sector 22 se incluye aquí pues el yacimiento de Terrazas del Manzanares se excluye (DELIBES y FERNÁNDEZ MIRANDA, 1987).

\subsection{Tumbas y disposiciones generalizadas}

El ritual funerario característico de Cogotas I, el enterramiento en fosa (MONTERO, 2011: 333), es el único registrado hasta el momento con certeza en la Meseta Sur. No nos extrañaría que los hipogeos, utilizados por las comunidades del III milenio a.C. en la zona (BUENO et al. 2008), sigan usándose durante la Edad del Bronce igual que en otras áreas peninsulares de la Península (ALVES et al. 2010). Ahora bien, al margen de estas "estructuras en negativo", hipogeos y fosas, parece difícil que dólmenes, túmulos o cuevas, bien conocidos por las comunidades Cogotas septentrionales, quiten protagonismo a las fosas en las tierras del Tajo. La proximidad entre hipogeos y fosas se observa también en la presencia de nichos, verdaderas repisas abiertas en las paredes de la tumba. En el Tajo albergan enterramientos en tres yacimientos, todos ellos de adultos.

Ligado a las fosas siempre surge su cualidad de ocultación pero, según tenemos mejor documentación de campo, son necesarios planteamientos flexibles del tema (ESPARZA et al. 2012a: 271). La voluntad de presencia y permanencia de las tumbas observada en centurias previas (BARROSO et al. e.p.) no debería de ser rechazada de forma tajante en el conjunto de enterramientos Cogotas, por mucho que el registro muestre discordancias: tumbas esquivadas por estructuras posteriores, como la 23 de Caserío de Perales (INIESTA, 2006: 322), frente a otras cortadas por hoyos sucesivos, como la tumba 19 de Berrocales (ALIAGA y MEGIAS, 2011: 60) o el fondo 13A del Sector 22. El propio traslado de restos y su agrupación, más aun si proceden de centurias diferentes como ratifica el C14 en la Meseta Norte (ESPARZA et al. 2012b: 120), no puede entenderse sin un recuerdo claro de esa dispersión.

La presencia de piedras, incluso grandes lajas, es frecuente en las fosas. Afloran en superficie, siendo visibles, o aparecen en el interior junto a los enterramientos. Bordean, delimitan e incluso ayudan al acomodo del difunto, como Príncipe 11 (ORTIZ Y LÓPEZ, 1997: 635); forman la base sobre la que se coloca el cuerpo (Tumba 3 de Berrocales), cierran covachas (Tumba 6 y 15 de Berrocales) o cubren el enterramiento (Tumba 11, Caserío de Perales). No faltan alusiones a la presión ejercida por las piedras sobre los restos, humanos y materiales, en el enterramiento del fondo 20 de Caserío de Perales (BLASCO et al. 1991a: 62-63) o en el hoyo 3 de La Dehesa, como si hubieran sido "arrojadas" (MACARRO, 2002: 110) sobre los cráneos.

Se reitera la presencia de bloques de sílex y cuarcitas, además del granito de molinos como los contenidos en sepulturas de Caserío de Perales (BLASCO et al. 1991a: 60) o Pista de Motos (VIRSEDA y DOMÍNGUEZ, 2008: 25). La inclusión de estos materiales líticos, susceptibles de ser transformados, debe tener más interés que el de mero relleno.

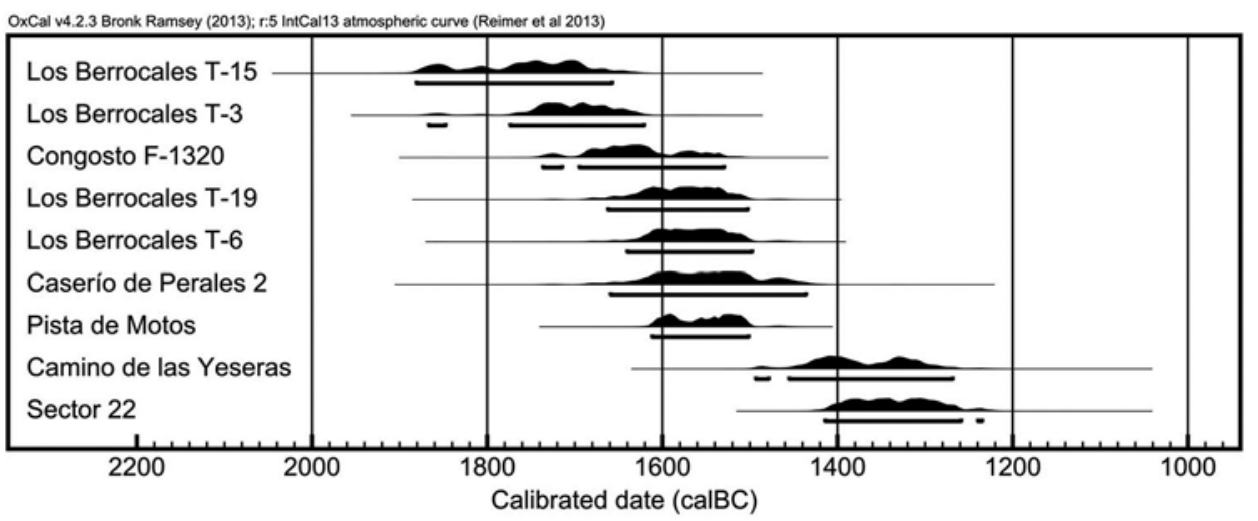

Fig. 5. Dataciones C14 calibradas de enterramientos Cogotas I de la Meseta Sur. / C 14 calibrated dates of the Cogotas I burials in the Southern Iberian Meseta. 
Hay también rasgos comunes en la colocación de los individuos. La mayoría están flexionados en decúbito lateral e incluso si el tronco se sitúa en posición supina es raro no encontrar las extremidades flexionadas. Cuando se usan posturas más caprichosas como la colocación boca abajo, hasta el momento sólo en niños (13A de Sector 22 y Camino de las Yeseras), hay una hiperflexión de los cuerpos a modo de paquetes óseos. Estas posiciones contraídas, sin ser exclusivas de Cogotas I, sólo se justifican por cuestiones de espacio en los nichos y ligadas a situaciones laterales dentro de la estructura que dejaría una reserva de espacio para nuevos enterramientos.

Sólo en dos varones sabemos el lado de inclinación del cuerpo y hay un número próximo de féminas en ambas posturas. Así, la preferencia del lado derecho e izquierdo para reposo de hombres y mujeres, respectivamente, reafirmada en la Meseta Norte (ESPARZA et al. 2012a: 282), aún no puede contrastarse en el Tajo. Curiosamente este patrón de deposición es inverso en el Argar (ARANDA et al. 2008: 253-254)

\subsection{La heterogeneidad de modos funerarios}

Contamos con enterramientos primarios (34) y secundarios, incluyéndose aquí pocos ejemplos claros como los huesos dispersos del enterramiento 34 de Los Berrocales, el fondo 20 de Caserío de Perales y el individuo 2 del fondo 3 del Sector 22.

Sin embargo, frente a estos enterramientos formales, un buen número de fosas contiene restos óseos fragmentarios que obligan a pensar que el número de enterramientos secundarios fue elevado. Los encontramos en 6 yacimientos (12 fosas), con el mismo tratamiento que los desechos de fauna o restos materiales fragmentados que forman parten del relleno habitual de los hoyos (Tabla III).

Son restos parciales, incluso con conexiones anatómicas, como la mano localizada en Arenero de Soto (MARTíNEZ y MÉNDEZ, 1983: 232), y el 50\% corresponde a fragmentos craneales, mandibulares o dientes. Sin fecha absolutas no es fácil pronunciarse sobre su cronología pues los hay en los inicios (ESPARZA et al. 2012a: 272) y también en la plenitud de Cogotas. Pesa en ello la consideración de la práctica como un deterioro de la norma funeraria tradicional (INIESTA, 2006: 654), sin embargo conocemos ejemplos más antiguos (ROJO et al. 2008: 376). En el Tajo hay yacimientos en los que suponen una práctica minoritaria frente a los individuos "completos", primarios o secundarios, y otros en los que invierten la proporción. A las 40 tumbas de los Berrocales hay que sumar sólo cuatro fosas con restos parciales (VEGA, 2009: 16), mientras en La Fábrica de Ladrillos son seis, de las ocho fosas con restos humanos.

La importancia de los restos craneales se plasma también en testimonios que conviene diferenciar porque su selección, intencionalidad y cuidada deposición no ofrecen duda: el fondo 3 del Sector 22, de cuyo muerto 2 sólo se incluye su cráneo, y el fondo 3 de La Dehesa de Alcalá de Henares, con dos cráneos colocados con las caras contrapuestas (MACARRO, 2002: 109)

Para el origen de los restos fragmentarios se han planteado causas múltiples, fortuitas o intencionadas, (BLASCO et al. 1991a: 64; ESPARZA et al. 2008: nota 52). Sin embargo, su asociación otros individuos más o menos completos (ESPARZA et al. 2012b), sirve para considerarlos fuera de toda eventualidad en los hoyos. Algunos, como un fragmento de húmero del fondo 128 de La Fábrica de Ladrillos, con huellas de mordeduras de carnívoro, podrían proceder de cuerpos expuestos a la intemperie (BLANCO et al. 2007: 64), en la línea de lo documentado en Tordillos (ESPARZA et al. 2012b). En cualquier caso, es difícil abstraerse a la idea de un cierto trasiego y manipulación de restos, incluso entre los propios hoyos, que podrían no ser cerrados de forma permanente tras la deposición, con lo que todos los restos secundarios no procederían automáticamente de acciones de exposición a la intemperie. El enterramiento 16 de Los Berrocales, primario, carece de huesos de las piernas pero sí de pies en conexión anatómica. El estudio antropológico de campo determinó un enterramiento primario en espacio no colmatado (VEGA,
Yacimientos

\begin{tabular}{|c|c|c|}
\hline Alarilla & Dientes & MENDEZ, 1993 \\
\hline La Fábrica 56-57 & Frag. Parietal & \multirow{6}{*}{ BLANCO et al. 2007} \\
\hline La Fábrica 112 & Frag. Neurocráneo & \\
\hline La Fábrica 119 & Posible resto humano & \\
\hline La Fábrica 128 & Frag. Húmero & \\
\hline La Fábrica 130 & Frag. Diáfisis peroné & \\
\hline La Fábrica 147 & Frag. Maxilar & \\
\hline El Negralejo F-9 & Frag. Neurocráneo, 5 incisivos y un canino & BLASCO, 1983 \\
\hline Aguas Vivas - UE261 & Frag. Cúbito izq. & \multirow{2}{*}{$\begin{array}{c}\text { CANTALAPIEDRA e ISMODES } \\
2010\end{array}$} \\
\hline Aguas Vivas -UE 911 & 2 cabezas de fémur & \\
\hline Arenero de Soto F-15 & Mano en conexión anatómica & MARTINEZ y MENDEZ, 1983 \\
\hline Caserío de Perales F-35 & Mandibula varón jóven & BLASCO et al. 1991 \\
\hline
\end{tabular}

Tabla 3: Restos óseos aislados Cogotas I de la Meseta Sur. Table 3: Cogotas I human remains in the Southern Iberian Meseta. 
2009: Tabla I) quizás favorecido por algunos bloques de sílex localizados en la tumba (ALIAGA y MEGÍAS, 2011: 59). Lo cierto es que el yacimiento tiene hasta 11 enterramientos en espacios no colmatados y muchos más están incompletos o tienen desplazamientos por alteraciones postdeposicionales abiertas a causas muy diversas. Viene al caso recordar ejemplos peninsulares de tumbas reabiertas durante la Edad del Bronce donde no se expolian los ricos ajuares, sino se sustraen los restos óseos (ARANDA et al. 2008: 234).

\subsection{Individuales y más}

La ausencia en el Tajo de enterramientos colectivos, acumulativos o múltiples, que sí aparecen en cuevas o poblados de fondos de la Meseta Norte (ABARQUERO, 2005; ESPARZA et al. 2012b), es destacable. Son mayoritarios los enterramientos individuales (68\%), presentes en todos los yacimientos que tienen más una tumba de esta etapa; hay 6 enterramientos dobles, en cinco yacimientos, y dos tumbas triples (11\%). Si además valoramos el carácter primario o secundario de los enterrados, las combinaciones aumentan. A los enterramientos individuales secundarios, ya señalados, se suman dobles en los que hay primarios o secundarios, cuestión que también se reproduce en los triples como Pista de Motos o el hoyo 3 del Sector 22. La voluntad de aglutinar varios enterramientos en una sola fosa, es innegable, pues no sería difícil utilizar estructuras independientes.

No menos interesante es la reunión de enterramientos primarios y secundarios, y el último en morir, ocupando la posición superior, como vimos en la tumba 3 del Sector 22 o en varios yacimientos del Duero (ESPARZA et al. 2012b: 102). La intención de reagrupación en el mismo hoyo, al margen del tiempo que separe la muerte de cada uno, es lo primordial, por encima de uno u otro tipo de enterramiento y de la solemnidad o descuido en su deposición. El enterramiento primario superior pone fin a la circulación de los restos de los anteriores, si bien es difícil precisar la motivación de fondo, afectiva o social.

La reiteración de enterramientos dobles y triples, sucesivos o simultáneos (MONTERO, 2011: 337 y 338; ESPARZA et al. 2012b: 281), hoy también bien visible en contextos ratificados de individuales como el Argar (ARANDA et al. 2008: 254), se constata en Cogotas I. En el Tajo, además, tienen mayor presencia de mujeres y en todos se incluye algún enterramiento infantil por lo que, aun primando la individualidad, sigue patente la importancia del núcleo familiar de centurias anteriores. Los rangos de edades y sexo de los enterrados, por ejemplo los dos adultos e infantil de Pista de Motos, son bastante plausibles como núcleo parental. De esta forma los vínculos, ratificados por paleogenética en la Meseta Norte (ESPARZA et al. 2012a: 279 y 306), podrían reproducirse en el Tajo.

En relación a las tumbas múltiples se han planteado dudas sobre lo improbable de la muerte simultánea de los enterrados, tomando peso la idea de su excepcionalidad y causalidad anómala (ESPARZA et al. 2012a: 299-300). En la Meseta Sur, cualquier postura sobre este tema debe abordarse, como poco, desde el milenio anterior donde los individuos enterrados en fosas múltiples representan, en algunos yacimientos, más de la mitad de la población enterrada (BARROSO et al. ep.). Las fosas no suponen un uso fluido del contenedor funerario pero no por ello son siempre de un único uso, siendo difícil establecer el tiempo que separa los decesos y apreciar diferencias arqueológicas.

\subsection{La población enterrada}

La determinación de sexo y edad (en 44 individuos), muestra una presencia de 24 adultos (con sexo determinado para 12 mujeres y 8 hombres), 4 juveniles (2 hombres y 2 mujeres) y 16 infantiles. La edad de muerte no está asociada a una práctica funeraria. Hay infantiles en enterramientos individuales, dobles y triples, en posición primaria o secundaria, y lo mismo ocurre con los adultos.

Sin embargo, los datos sobre edad están obtenidos mediante metodologías tan dispares que dificultan un trato porcentual riguroso y aconsejan valoraciones con intervalos de edad amplios. Faltan los perinatales, no hay ningún niño menor de dos años, y también los mayores de 50, con una única posibilidad en la mujer enterrada en Pista de Motos. Estos aspectos resultan relevantes por su contraste con uno de los yacimientos del Tajo con mayor registro funerario de comienzos de la Edad del Bronce, Loma del Lomo. El estudio antropológico determinó la existencia casi exclusiva de niños e individuos seniles (VALIENTE, 1992: 207).

El análisis de la distribución de edades de muerte en la totalidad de los yacimientos recogidos muestra una estructura inesperada (Fig. 6) ya que son más abundantes los individuos en el grupo de 5-9 años que en el de 0-4 años. Se trata de un perfil de mortalidad poco habitual, ya una vez que se han superado los primeros años de mayor riesgo, en los que la probabilidad de muerte, en condiciones naturales, es mayor (GONZÁLEZ, 2008: 6061). En todo caso, la proporción de individuos cuya estimación de la edad no ha sido posible es grande, de forma que el perfil observado puede albergar un amplio margen de incertidumbre.

Comparándolo con los datos de la población de la Meseta Norte (ESPARZA et al. 2012a:290), se observa aquí una mayor proporción de individuos entre 0 y 4 años, y diferencias en el índice de juventud (BOCQUET-APPEL Y MASSET, 1977). Este duplica sobradamente en la Meseta Sur el calculado para la Meseta Norte (0.75 frente a 0.32), aunque la inclusión como adultos del conjunto de individuos de edad sin determinar en el cálculo del índice de juventud hace que ambos se aproximen mucho.

Los autores del citado estudio concluyen que podrían ser enterrados sólo los fallecidos a partir de los seis meses de vida y que la población juvenil está sobrerrepresentada en el registro funerario Cogotas siendo, en consecuencia, un grupo seleccionado para ocupar las tumbas (ESPARZA et al. 2012a: 290-294). Curiosamente 


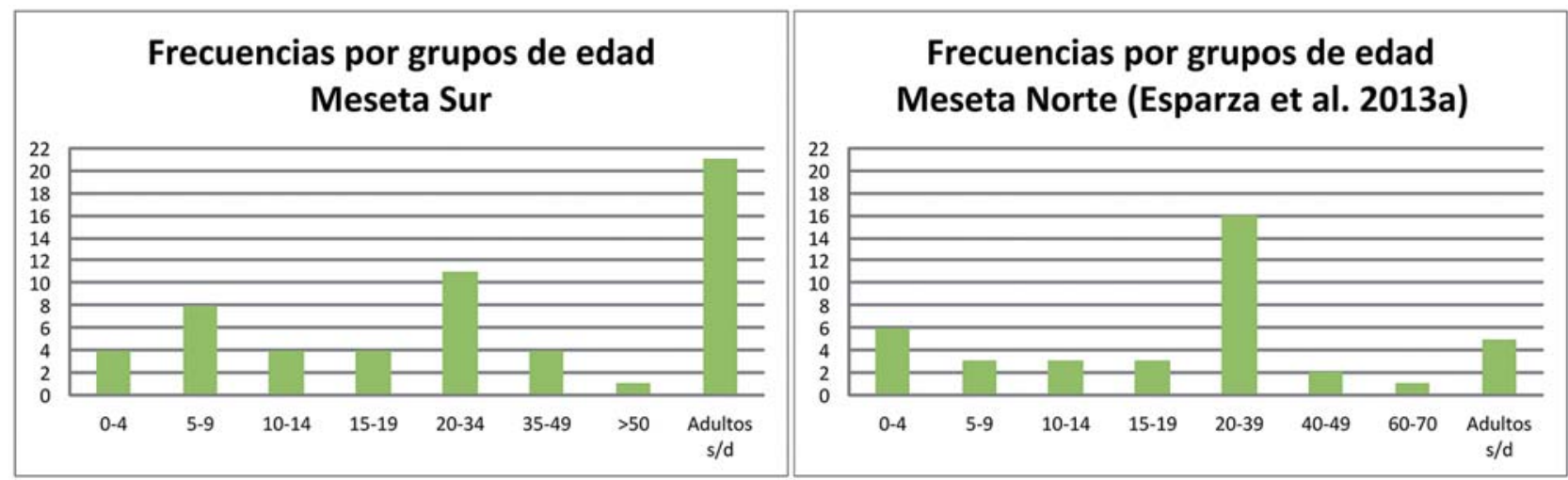

Fig. 6. Comparación de la distribución por edades de la muestra analizada en el presente trabajo y la correspondiente a la Meseta Norte. / Comparison of the ages distribution between the sample analysed in this paper and the study of the Northern Meseta.

enclaves como Tordillos, el yacimiento con mayor número de enterramientos de este momento en la Meseta Norte, 22 individuos (ESPARZA et al. 2012b:99), no tiene ningún juvenil enterrado.

Evidentemente los resultados obtenidos son muy dispares y llaman a la prudencia a la hora de establecer conclusiones sobre los aspectos funerarios de estos grupos humanos, que siempre podrían argumentarse mejor dentro de una misma población arqueológica.

\subsection{Objetos y animales en la tumba}

El ajuar y las ofrendas llevadas a la tumba por las comunidades Cogotas son reducidos (ESPARZA et al. 2008: 72 y 2012a: 267; BLASCO, 2012: 214). En la Meseta Sur no sólo son inusuales, sino que ni uno sólo podría considerarse ostentoso, entendiendo por tal su manufactura en materias exógenas, escasas o con una inversión significativa de trabajo en su configuración.

A dos punzones metálicos y los colgantes de caliza del enterramiento de Príncipe 11 (ORTíZ y LÓPEZ, 1997), más en la línea de elementos personales de adorno o de la vestimenta, se suman cuatro recipientes cerámicos, dos de ellos colocados junto a la cabeza del enterrado (BLASCO et al. 1991a: 58) como en Sector 22. Todas son piezas lisas, nada excepcionales ni fabricadas para la ocasión, que cierran en la tumba su ciclo de uso. Su contenido debió ser lo sustancial, como proponíamos en el recipiente del sector 22 .

Hay, además, acumulaciones de materiales y fauna. En la tumba 20 de El Caserío de Perales los recipientes rotos encontrados podrían haber servido de contenedor de deposición de los restos desmembrados del individuo (BLASCO et al. 1991a: 68) y reproducir un fraccionamiento similar entre cuerpo y objeto (BRÜCK, 2006:80). En Pista de Motos, la tumba se selló con molinos de granito, una pesa de telar y grandes contenedores fragmentados "in situ" (VIRSEDA y DOMíNGUEZ, 2008: 25). En ambos casos más que piezas relevantes parecen enseres de viviendas que trasponen lo domestico a la tumba mostrando una ideología funeraria que enfatiza la producción.
La presencia de animales como ofrendas tampoco se prodiga en los enterramientos del Tajo, siendo los nueve ovicaprinos de la tumba 13A del Sector 22 una de las más numerosas adscritas a Cogotas I. La disposición estructurada de los restos, sobre y con el enterrado, la importante presencia de animales jóvenes, sin peso óptimo pero mejor calidad cárnica y qué sea solo una la especie representada, casi un pequeño rebaño de corderos, son algunas de las características más destacadas. Su asociación al vaso cerámico sólo la conocemos en el yacimiento navarro de Cortecampo II (RAMOS, 2007).

Sólo hay dos ejemplos más de ofrendas de fauna en el Tajo que contrastar con el Sector 22 por lo que poco puede explorarse sobre pautas, cantidad, variedad o acceso de los inhumados, salvo señalar su asociación a enterramientos infantiles y la presencia de canidos, una especie con varias vertientes de uso (ALBIZURI et al. 2011; BLASCO, 2012: 211; SÁNCHEZ POLO, 2012: 458).

No faltan en el Tajo interpretaciones de la cerámica con roturas deliberadas y, en especial, los depósitos de animales como testimonios de banquetes o celebraciones de consumo comunitario (ALIAGA y MEGÍAS, 2011:82; MONTERO, 2011: 312; SÁNCHEZ POLO, 2012: 459). Sin embargo, a día de hoy, faltan evidencias en el registro sobre los escenarios de preparación y celebración de dichos banquetes. La fauna depositada en las tumbas, como en el Sector 22, nos muestra más alarde que consumo de comida.

\subsection{Vida y muerte unidas}

La asociación entre áreas de habitación y funerarias, característica de Cogotas I, es otra de las máximas en la Meseta Sur, pero con una imagen generalizada de que los enterramientos menudean sin orden entre las estructuras (ESPARZA et al 2012a: 270; BLASCO, 2012: 201; MONTERO, 2011: 334). Sin embargo, resulta contradictorio que comunidades con esos vínculos familiares comentados y reagrupaciones claras dentro de la tumba, después carezcan de criterio espacial alguno de deposición dentro del área de ocupación. En definitiva, extraña que la convivencia vivos-muertos no fuera organizada. 
Al respecto se han expuesto varias ideas ligadas a la organización y dinámica de los hábitats: Por un lado, desde la continuidad de poblamiento registrada durante el III y II milenio a.C. en la Meseta Sur que conlleva una organización interna del espacio productivo que también implica al mundo funerario. Los enterramientos se agrupan en áreas determinadas, asociadas a zonas de producción o su periferia (DÍAZ DEL RÍO, 2001: 152 y 154). Por otro, desde parámetros generales que en los poblados Cogotas I se han realizado principalmente a partir de "ausencias", las de las viviendas siempre esquivas. Los enterramientos, más concentrados durante el Bronce Antiguo, tendrían después una situación perimetral, ligada a las viviendas (BLASCO, 2004: 375), ocupando extensiones menores y bien diferenciadas de los núcleos del III milenio a.C. y con una reducción del número de tumbas (LIESAU et al. 2008: 99; RíOS, 2011a: 361).

Un repaso de los yacimientos con mayor número de enterramientos muestra claramente problemas de delimitación, topográfica o espacial, la falta de fechas y con ello las dificultades de determinar criterios de localización de los enterramientos dentro del área ocupada. Se perciben agrupaciones de estructuras muy próximas entre sí, que permiten disyuntivas semejantes a las planteadas en otros yacimientos de la Edad de Bronce de la región muy próximos entre sí (DÍAZ DEL RÍO y VICENT, 2006: 28). La población se reorganiza espacialmente en yacimientos amplios con áreas de diferente funcionalidad o espacios ocupados por agrupaciones dispersas y reducidas.

- El Caserío de Perales, en Getafe (BLASCO et al. 1991a), un verdadero mosaico de yacimientos hace una década (DÍAZ DEL RIO, 2001: 261-270), en los últimos años se ha ampliado, pero el aumento de terreno excavado no ha proporcionado un equitativo implemento de los elementos de vertebración interna de la ocupación. En él se abrieron cuadrículas en un área de $4 \mathrm{H}$ localizándose 500 fondos en $2 \mathrm{H}$ de terreno (INIESTA, 2006). A escasos 500 m se sitúa Arenero de Soto I (MÉNDEZ y MARTíNEZ NAVARRETE, 1983), con $244 \mathrm{~m}^{2}$ abiertos y 33 fondos excavados, aunque se indica la existencia de estructuras en una superficie de $10.406 \mathrm{~m}^{2}$. En una segunda intervención, a

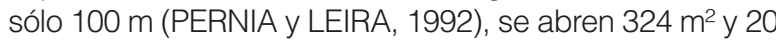
hoyos. Recientemente se actúa en Caserío de Perales 2, con $200 \mathrm{~m}^{2}$ y 6 fondos (SANABRIA et al. 2007: 229). En el entorno próximo, algo más de un $1 \mathrm{Km}$, se sitúa Perales del Río, donde en $118 \mathrm{~m}^{2}$ se excavan 13 estructuras, si bien el yacimiento alcanzaría casi las $4 \mathrm{H}$. (BLASCO et al. 1991b:41). Ni aquí, ni en Arenero de Soto, se encontraron enterramientos, pero sí en Caserío de Perales, siete en total, a los que sumar uno seccionado por una zanja en Caserío 2 y otro más a escasos 200 m (POS.B-22 Butarque). En esta última intervención, el seguimiento de las zonas afectadas por la apertura de un gaseoducto, se encontraron varios tramos con fondos de la Edad del Bronce que confirman la notable ocupación de la zona (UNGÉ y RUIZ, 2004). Nueve enterramientos en $1070 \mathrm{~m}^{2}$ con 617 hoyos.

Los enterramientos se concentran en el tramo de El Caserío de Perales, el de mayor extensión excavada, mos- trando la relación proporcional entre mayor número de estructuras abiertas y mayor número de enterramientos. La menor densidad de estructuras respecto a Arenero de Soto, propuesto como espacio inmediato a un área de habitación (DÍAZ DEL RíO, 2001: 264), situaría los enterramientos en un perímetro externo amplio que parece acotarse más en la interpretación del Caserío de Perales como un espacio central abierto rodeado por cabañas de unos $10 \mathrm{~m}$ de diámetro delimitadas a partir de las agrupaciones de hoyos y áreas de distintas actividades productivas (BLASCO, 2012: 202; INIESTA, 2006: 625-626) (Fig.7B). Los enterramientos se localizan en la periferia de las viviendas, ocupando áreas de cierta densidad de estructuras, alguna de ellas delimitada como de taller. El uso del espacio durante el Bronce Final parece evitar expresamente los lugares con restos funerarios, lo que implicaría una presencia "conocida" y estable, si bien puede pesar en ello la consideración de todos los enterramientos coetáneos sin tener fechas absolutas.

- Los Berrocales (Fig. 7A), es una amplia superficie que agrupa varios yacimientos de la Edad del Bronce evidentemente relacionados: El Espinillo, Alto de las Peñuelas - Sector IV, que reúnen $187.579 \mathrm{~m}^{2}$ y 1092 estructuras (RíOS, 2011b: 7; ALIAGA y MEGÍAS, 2011:21), y La Ca-

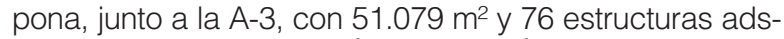
critas al Bronce Medio (GÓMEZ y EXPÓSITO, 2008b: 323). En su planimetría se ven cuatro agrupaciones de estructuras, que sólo llegan a distanciarse claramente dentro de Alto de las Peñuelas - Sector IV, por no más de $150 \mathrm{~m}$. Se observa, también, una gradación en la densidad y número de estructuras, siendo los cerca de $82.000 \mathrm{~m}^{2}$ de El Espinillo, los de mayor entidad, con 814.

Con una única vivienda, de fecha imprecisa (ALIAGA y MEGÍAS, 2011: 42), se insiste en similitudes en todos los sectores reproduciéndose espacios circulares sin estructuras (de hasta $50 \mathrm{~m}$ ), circundados por series de hoyos que repiten tipologías y funcionalidades semejantes (hoyos simples, estructuras cortadas, hoyos de poste, con hogares o depósitos de fauna) (GÓMEZ y EXPÓSITO, 2008a y b; MEGÍAS y EXPÓSITO, 2008). Sin embargo hay una diferencia clara, no hay enterramientos en La Capona. Los enterramientos se limitan a Espinillo y Sector IV, especialmente en su tramo norte, compartiendo fechas idénticas y mayor densidad de estructuras, con mayor superposición y más capacidad que las localizadas en La Capona.

- La Dehesa (Alcalá Henares) podría llegar a las $3 \mathrm{H}$, localizándose 115 estructuras y siete enterramientos (MACARRO, 2002: MARTíN y MENDUIÑA, 2003). La excavación cubrió algo más $12.000 \mathrm{~m}^{2}$, con tres sectores. El A (Fig. 7C), es la de mayor densidad de estructuras y en el que se concentran los enterramientos, en escasos $10 \mathrm{~m}^{2}$ y formando un medio círculo. Se destacan seis espacios libres de estructuras entorno a los cuales se disponen las cabañas (12 $\mathrm{m}^{2}$ de media). Relevante es el espacio 1, el mayor de todos $\left(300 \mathrm{~m}^{2}\right)$, que dispone de un gran silo central y 17 cabañas, concentrándose en cuatro de ellas 6 enterramientos (MACARRO, 2002: 217-232). Estamos ante el primer yacimiento en el que se avanza un número mínimo de viviendas, 25, y el único que plantea para Cogo- 


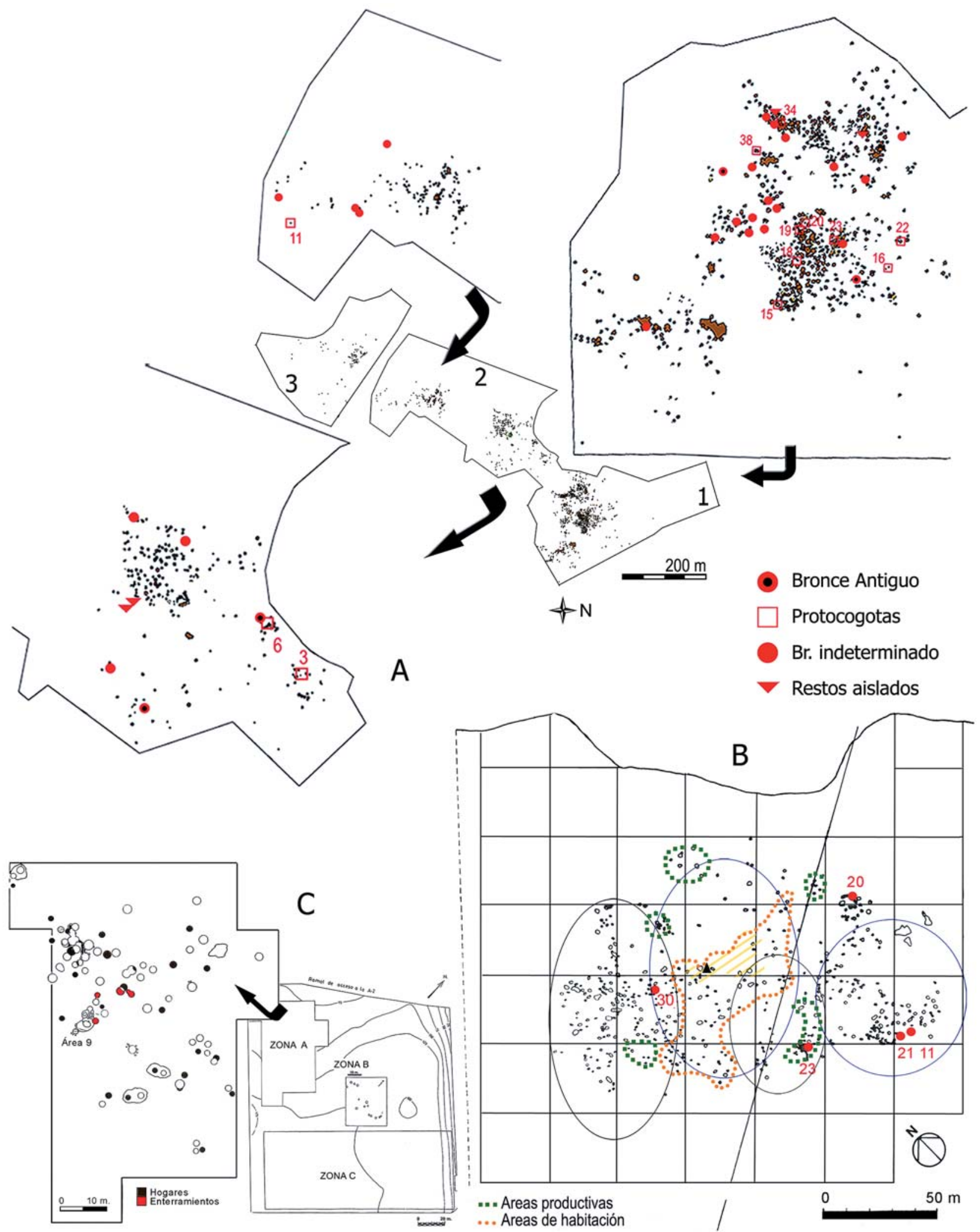

Fig. 7. Planimetrías de yacimientos del a Edad del Bronce en Madrid con la localización de los enterramientos. A) Los Berrocales: 1.- El Espinillo; 2.- Alto de las Peñuelas - Sector IV; 3.- La Capona (a partir de Megías y Expósito, 2008). B) La Dehesa (a partir de Macarro, 2002). C) El Caserío de Perales (a partir de Blasco et al. 1991a: Fig. 1; Iniesta 2006; fig. 8.1 y 8.2). / Plan of Bronze Age sites from Madrid with the location of burials. A) Los Berrocales: 1.- El Espinillo; 2.- Alto de las Peñuelas - Sector IV; 3.- La Capona (after Megías and Expósito, 2008). B) La Dehesa (after Macarro, 2002). C) El Caserío de Perales (after Blasco et al. 1991a: Fig. 1; Iniesta 2006; fig. 8.1 y 8.2). 
tas I, la asociación de enterramientos bajo las casas. Al respecto hay que admitir que la caracterización de las estructuras como cabañas es diferente al resto de los yacimientos. Estaríamos ante una situación bien distinta, muchas casas sin muertos.

\subsection{Salud y enfermedad}

Tenemos análisis procedentes de una muestra de (33) individuos localizados en seis intervenciones distintas, de los que 22, presentan algún signo patológico (Tabla IV). De ellos 7 son infantiles, 2 juveniles y el resto adultos, determinándose el sexo en sólo 13 individuos de los que 9 son femeninos. Evidentemente los signos patológicos solo aparecen cuando se hace un análisis de cierta profundidad, que produce a la vez más información sobre las variables biológicas individuales, y en nuestro caso coincide con las intervenciones recientes.

Centrando el análisis en los 22 individuos que presentan algún signo, una gran parte de ellos presenta patología oral (81\%; 17 casos). De ellos, el 60\% (10 casos) presenta más de un indicador paleoestomatológico. El fenómeno más frecuentemente observado es la caries, que afecta al $41 \%$ de los individuos; cuatro individuos presentan además pérdida dental premortem, cuya principal causa es la anterior. En el caso del sector 22, el grado de las lesiones y el número de piezas afectadas es muy bajo para lo que se esperaría de dientes de leche, al final de su etapa útil y en individuos mayoritariamente vegetarianos.

En orden de frecuencia decreciente, a continuación aparecen los depósitos de cálculo y la hipoplasia del esmalte dental, con 7 casos (32\%), siendo el resto de signos patológicos orales mucho menos frecuentes. Caries, atrición, pérdida dental premortem y abscesos son más frecuentes en individuos masculinos, mientras que cálculo e hipoplasia del esmalte dental aparecen más asiduamente en femeninos. La mayor parte de estos caracteres se observan en individuos adultos, aunque se encuentran caries e hipoplasia del esmalte dental desde el grupo 5-9 años. Tanto el número de indeterminados respecto al sexo y la edad como los bajos tamaños muestrales impiden probar estadísticamente la asociación entre estas variables.

\begin{tabular}{|c|c|c|c|c|c|c|c|c|c|c|c|c|}
\hline & & \multirow{2}{*}{\begin{tabular}{|c|} 
Fenómenos \\
porosos
\end{tabular}} & \multicolumn{6}{|c|}{ Patología oral } & \multirow{2}{*}{\begin{tabular}{|c}
$\begin{array}{c}\text { Patologia } \\
\text { axial }\end{array}$ \\
\end{tabular}} & \multirow{2}{*}{$\begin{array}{l}\text { Patología } \\
\text { articular }\end{array}$} & \multirow{2}{*}{\begin{tabular}{|l|} 
Patología \\
traumática
\end{tabular}} & \multirow[t]{2}{*}{ Miscelánea } \\
\hline & & & Caries & Sarro & Hipoplasia & Atrición & Abceso & PAD & & & & \\
\hline \multicolumn{13}{|c|}{ Caserío de Perales (Robles et al. 1991) } \\
\hline \multicolumn{13}{|c|}{\begin{tabular}{|l|l|} 
Fondo 11 (PR-07) & (30-42 a.) \\
\end{tabular}} \\
\hline Fondo 21 (PR-04) & ㅇ (30-50 a.) & & & & & & & & & & & \\
\hline \multicolumn{13}{|c|}{ Fondo 23 (PR-05) ? (9 a.) } \\
\hline (PR-06) & ? (4-5 a.) & & & & & & & & & & & \\
\hline \multicolumn{13}{|c|}{\begin{tabular}{|l|l|} 
Fondo 30 (PR-01) & $\sigma^{\prime \prime}(20-25$ a.) \\
\end{tabular}} \\
\hline \multicolumn{13}{|c|}{ El Congosto (Martín, 2006) } \\
\hline UE- 1324 & Q (> 40 a.) & & & & & & & & & & & \\
\hline \multicolumn{13}{|c|}{ ERAR Butarque (Ungé y Ruiz, 2004) } \\
\hline F-K-XVI & Q $(25-30$ a.) & & & & & & & & & & & \\
\hline \multicolumn{13}{|c|}{ Los Berrocales (Vega, 2011) } \\
\hline \multicolumn{13}{|c|}{\begin{tabular}{|l|l} 
Enterramienti 3 & ?? (adulta) \\
\end{tabular}} \\
\hline \multicolumn{13}{|c|}{\begin{tabular}{|l|l|} 
Enterramiento 6 & क? (adulta) \\
\end{tabular}} \\
\hline Enterramiento 11 & ? (adulto) & & & & & & & & & & & \\
\hline Enterramiento 15 & ? (adulto) & & & & & & & & & & & \\
\hline \multicolumn{13}{|c|}{\begin{tabular}{|l|l|l} 
Enterramiento 16 & $\sigma^{7}(32-34,5$ a.) \\
\end{tabular}} \\
\hline \multicolumn{13}{|c|}{\begin{tabular}{|l|l|} 
Enterramiento 19 & $\sigma^{7}(16-17$ a.) \\
\end{tabular}} \\
\hline \multirow[t]{2}{*}{ Enterramiento 22} & 오 (25-45 a.) & & & & & & & & & & & \\
\hline & $\begin{array}{l}\text { (6-8 a.) } \\
\end{array}$ & & & & & & & & & & & \\
\hline \multicolumn{13}{|c|}{\begin{tabular}{|l|l|} 
Enterramiento 23 & (28-38 a.) \\
\end{tabular}} \\
\hline \multicolumn{13}{|c|}{ Sector 22 (Candelas y González, 2010) } \\
\hline Fondo 3 (M-1) & ? (10 a.) & & & & & & & & & & & \\
\hline$(\mathrm{M}-3)$ & ? (9a.) & & & & & & & & & & & \\
\hline F.13A & ? (10 a.) & & & & & & & & & & & \\
\hline \multicolumn{13}{|c|}{ La Dehesa (Marinas, 2014) } \\
\hline A22 (indiv. 3) & $\sigma^{7}(21-25$ a.) & & & & & & & & & & & \\
\hline $\mathrm{A} 22 \mathrm{~W}$ & ? (8-11 a.) & & & & & & & & & & & \\
\hline$A-21$ & $O_{(14-16 a)}$ & & & & & & & & & & & \\
\hline
\end{tabular}

Tabla 4: Signos patológicos en los enterramientos Cogotas I de la Meseta Sur. / Table 4: Pathological signs from Cogotas I burials in the Southern Iberian Meseta. 
La hipoplasia del esmalte dental se considera un indicador inespecífico, que mayoritariamente suele relacionarse con periodos de malnutrición y/o infección. En Sector 22 se estima su edad de formación entre los 3 y 5 años (individuo 13 A) y entre los 2 y 3 años (Hoyo 3).

Los cuatro casos de fenómenos porosos (18\%), se concentran en edades infantiles y juveniles (todos menores de 20 años). La existencia de cribra femoral (POLO, 2000) se documenta en el individuo de 10 años del Sector 22 (13A). La aparición de fenómenos porosos tiene como diagnóstico más repetido el de anemia ferropénica, aunque no puedan descartarse otras enfermedades nutricionales ni las anemias hereditarias.

No se ha encontrado signo alguno de enfermedad tumoral ni infecciosa. El hecho de no encontrarse ningún signo infeccioso puede ser relevante, dado que estas últimas podrían ser las principales responsables de episodios de crisis de mortalidad.

Las dos únicas lesiones traumáticas detectadas son craneales y afectan a dos mujeres adultas de Los Berrocales. El Espinillo cuenta con hasta 5 individuos con contusiones de este tipo (VEGA, 2009: 37), todos adultos, quedando excluidos el resto de grupos de edad de este tipo de lesiones. La dificultad estriba en diferenciar si su causa es accidental o consecuencia de un enfrentamiento interpersonal. En los dos enterramientos que nos ocupan, se trata de lesiones con un hundimiento superficial en la sutura coronal y frontal que pueden ser consecuencia de traumatismos. Además, en la mujer de la tumba 23, se asocia a una perforación rectangular consecuencia de un traumatismo perimortem (VEGA, 2009: 38).

Con respecto a las lesiones de tipo artrósico, tanto axiales (5 casos) como articulares (4 casos), solo se asocian en un sujeto (La Dehesa 21). Este individuo está actualmente siendo objeto de un estudio más profundo por los especialistas, dada la coincidencia de varios indicadores poco frecuentes en la literatura. Estas lesiones aparecen en más ocasiones en individuos femeninos y nunca antes de los 15 años.

También se han encontrado algunos signos que se han atribuido a la repetición sistemática de determinados movimientos, probablemente fruto de actividades cotidianas, como la deformación escapular de una mujer Caserío de Perales atribuida a cargas reiteradas (BLASCO et al. 1991: 61). Es necesario ser prudentes en la interpretación de este tipo de signos, ya que pueden estar relacionados con movimientos implicados en actividades físicas muy diversas.

\section{4.- CONSIDERACIONES FINALES}

Hemos presentado nuevos datos obtenidos en los enterramientos Cogotas I del Sector 22, Yuncos. El yacimiento, a pesar de su falta de delimitación completa, se estructura en dos áreas, con los restos funerarios concentrados al suroeste. En sólo dos tumbas, que agrupan cua- tro enterramientos, concurren algunos aspectos peculiares del ambiente funerario de la cultura meseteña: la corta edad de los enterrados, la confluencia de enterramientos primarios y secundarios, el ajuar y las ofrendas de animales. Igual de interesante es la localización del yacimiento fuera del Área Nuclear de la cultura meseteña (ABARQUERO, 2005:147), el noreste de Toledo. La zona cuenta con gran densidad de hallazgos, incluidos ahora los funerarios, y suficientes elementos característicos de Cogotas I como para que este aspecto sea revisado. Se abren, pues, nuevas expectativas de estudio y contraste fuera del sector del Tajo madrileño que, hasta no hace mucho, concentraba todos los yacimientos o las fechas.

Inventariar los enterramientos Cogotas I en el Tajo, además de hacernos ver las singularidades de nuestro yacimiento, nos ha permitido destacar algunas cuestiones.

Una primera, muy evidente, es el importante cambio que suponen los enterramientos de la Edad del Bronce, al menos desde el $2^{\circ}$ cuarto del II milenio a.C., respecto a los conocidos en el milenio anterior, tanto cuantitativamente como en la variedad de contenedores funerarios (BUENO et al. 2005). Las agrupaciones funerarias no llegan al medio centenar que superan varias necrópolis calcolíticas, aun habiéndose duplicado en los últimos años.

La fosa es el elemento común y primordial en todos los enterramientos Cogotas I del Tajo, hasta el punto que desconocemos aun otro tipo de tumba. Podría ser un elemento prioritario frente a las distintas variantes del ritual, fragmentos o individuos completos, con o sin ofrendas, individuales o múltiples, siempre que se obtuviera un espacio para la eternidad en el territorio del grupo. Hasta en algunos individuos que pudieron ser expuestos al aire (ESPARZA et al. 2012b), éste primer lugar se torna transicional recurriéndose a los hoyos para preservar finalmente los restos, conectando intencionalmente ambas pautas funerarias, norma y excepción, e integrando en el registro arqueológico documentos de otra forma imperceptibles. No está de más recordar que no todas las estructuras debieron cumplir siempre la misma función, no todos debieron ser silos y podría haber alguna elección explicita que desconocemos. También, que aunque hablamos de preservación, está no supone siempre una expresa atención al cuerpo completo, ni a su perfecta colocación, siendo notable la presencia de restos óseos sin tratamiento solemne alguno. El yacimiento de La Fábrica de Ladrillos es un buen ejemplo al respecto.

La edad no es un factor discriminante en el acceso a los enterramientos Cogotas. Hay infantiles, juveniles y adultos, si bien cualquier conclusión sobre demografía se enfrenta al reducido tamaño de la muestra y al sesgo arqueológico de las intervenciones. Rasgos como los patentes en Sector 22, el despunte de individuos juveniles, cuya mortalidad teórica, en condiciones naturales, es muy baja, como indican los trabajos de Demografía Histórica (LEDERMANN, 1969), o la baja presencia de perinatales, que teóricamente deben ser muy numerosos, podrían ser factores a tener en cuenta desde la práctica funeraria y su 
evolución en la Edad del Bronce, sin embargo es difícil pronunciarse. No hay duda que la cuestión es especialmente relevante en cuanto al patrón funerario planteado para Cogotas I, la exposición de cuerpos a la intemperie, lo que sitúa en el registro arqueológico una población funeraria muerta en circunstancias especiales, "a destiempo" (ESPARZA et al. 2012b: 118). Una mortalidad natural, la esperable de una población normal, dejaría fuera de toda eventualidad a los enterrados.

La escasez de ajuares y ofrendas es tan notoria que abre dudas sobre su papel como verdaderos atributos del inhumado. Cogotas I se desmarca de comportamientos anteriores y paralelos, como las distinciones y picos de riqueza que traza el Campaniforme (BUENO et al. 2005) o las desigualdades reflejadas en los bienes amortizados en los enterramientos argáricos (ARANDA et al. 2008). No puede decirse que la cultura material, entes u ornamentos, sean el medio de señalar la identidad de cada persona, ni haya especial preocupación ni competencia en ello. La única expresión social reside en las ofrendas alimenticias, alimentos elaborados y carne. Estas remiten a la riqueza económica, agropecuaria y excedentaria del grupo, si pensamos que se trata de ofrendas de calidad cárnica o de animales no consumidos. Ofrendas tan desproporcionadas como los nueve corderos del Sector 22 asociados a un infantil, que supondría un peso importante para la economía de una sola familia, parecen percibir al niño de los recursos de su grupo, socializarle. Para probar que en estas ofrendas hay previos eventos en cortesía al enterrado, encaminados a fortalecer la cohesión social, habrá que tener mejores registros, pero su propósito se habría cumplido con creces, pues ni en un solo enterramiento del Tajo se aprecia ostentación alguna de bienes.

La interpretación de los registros habitacionales y funerarios debe ser conjunta y hasta el momento no es posible. El estudio fraccionado de los yacimientos de la Meseta Sur impide conocer su extensión que, además, se ve dificultada por la falta de delimitaciones naturales y estructurales de huella arqueológica. La inexistencia de fosos impide defender un uso idéntico del suelo que el que se hace durante el III milenio a.C. pero desconocemos la reorganización espacial acometida y faltan estudios cuantitativos de los registros.

La parcial información que manejamos sólo trasluce un paisaje de yacimientos dispersos, en realidad formados por agrupaciones de estructuras, separadas por espacios, en ocasiones, de escasos metros, para las que volver a hablar de movilidad resulta paradójico. Sería necesario fechar y conocer bien sus registros para poder argumentar que estamos ante poblados con áreas vinculadas y funcionalmente distintas (DÍAZ DEL RÍO y VI-
CENT, 2006). En este contexto de comunidades de amplias, las agrupaciones funerarias, concentradas en algunas de estas áreas, pueden ser un argumento más de su variabilidad de uso. En su interior, más allá de la genérica asociación al espacio de habitación y producción (DÍAZ DEL RIO, 2001: 292), no se perciben criterios comunes en la organización interna de los enterramientos, y su asociación con viviendas necesita mejores elementos de definición.

Hay, por tanto, varias vías en las que seguir trabajando. Necesitamos conocer en profundidad los poblados Cogotas I4, su dinámica de desarrollo, el cambio o la continuidad que imponen en su organización sobre esos mismos espacios ocupados desde momentos neolíticos y con ello la disposición, o no, de verdaderos "sectores" funerarios.

Por otro lado, la inexistencia de bienes amortizados como indicador de desigualdades, invita a insistir aún más en los análisis antropológicos como elemento de aproximación a la sociedad Cogotas, manejando variables distintas como la dieta, indicadores patológicos y marcadores de actividad que pudieran establecer diferencias entre los enterrados. Del mismo modo es fundamental conseguir más fechas y mejorar nuestra información anatómica y tafonómica para descifrar alteraciones y episodios de deposición y descomposición de los cuerpos (DUDAY, 2006), sin dar por hecho el único uso de las fosas en las que elementos orgánicos pudieron tener importante presencia.

\section{5.- AGRADECIMIENTOS}

Nuestro agradecimiento a Antonio Dávila y Miguel Contreras por sus facilidades en la consulta de los expedientes de excavación del Museo Arqueológico Regional de la CAM.

Todas las analíticas han sido realizadas dentro del proyecto "Prácticas funerarias en la Prehistoria Reciente del interior del Tajo" (CCGH10-UAH/HUMA/ 5959).

\section{BIBLIOGRAFÍA}

\section{ABARQUERO, F.J. \\ 2005 Cogotas I. La difusión de un tipo cerámica durante la Edad del Bronce. Arqueología en Castilla y León 4. Junta de Castilla y León. Valladolid.}

\section{ALBIZURI, S. FERNÁNDEZ, M. \& TOMÁS, X.}

2011 Evidencias sobre el uso del perro en la carga durante el Bronce Inicial en la Península Ibérica: el caso de Can Roqueta II (Sabadell, Barcelona). Archaeofauna 20, 139-155.

${ }^{4}$ En la funcionalidad e interpretación de estos asentamientos no debería olvidarse el uso que se ha hecho de esos entornos hasta momentos recientes. En el caso del yacimiento de Los Berrocales (Gómez y Expósito 2008a y b) numerosas estructuras modernas para la extracción de sílex se intercalan, con tipologías muy semejantes, entre las prehistóricas. En el Sector 22, las arcillas explotadas actualmente en la zona pudieron interesar en el pasado. 
ALIAGA, R \& MEGÍAS, M.

2011 Los Berrocales (Madrid): un yacimiento de la Edad de Bronce en la confluencia Jarama-Henares. Patrimonio Arqueológico de Madrid/8. Universidad Autónoma de Madrid - Arqueomedia. Madrid.

ALVES, C., COSTEIRA, C., ESTRELA, S., PORFIRIO, E., SERRA, M., SOARES, A.M.M. \& MORENO, M.

2010 Hipogeus funerários do Bronze Pleno da Torre Velha 3 (Serpa, Portugal). O Sudeste no Sudoeste?. Zephyrus LXVI, 133-153.

ARANDA, G., MOLINA, F., FERNÁNDEZ, S., SÁNCHEZ ROMERO, M., AL OUMAOUI, I., JIMENEZ, S. \& ROCA, M.G.

2008 El poblado y necrópolis argáricos del Cerro de la Encina (Monachil, Granada). Las campañas de excavación de 2003-05. Cuadernos de Prehistoria y Arqueología de la Universidad de Granada 18, 219-264.

BARROSO, R. M.

2002 El Bronce final y los comienzos de la Edad del Hierro en el Tajo Superior. UAH- Diputación de Toledo. Madrid.

BARROSO, R., BUENO, P., BALBIN, R., VAZQUEZ, A. \& GONZALEZ, A.

e.p Nekropolen des 3. Jahrtausends v. Chr. im Zentrum der Iberischen Halbinsel. Madrider Mitteilungen.

\section{BARROSO, R., ROJAS, J.M., BUENO, P. \& GONZÁLEZ, A.}

2011 Dos enterramientos prehistóricos singulares del Sector 22 de Yuncos, Toledo. Estudio preliminar. Actas del Congreso "La muerte en el tiempo, arqueología e historia de hecho funerario en la provincia de Toledo" - UNED. Talavera de la Reina, 81-94

BLANCO, F. BLASCO, C., LIESAU, C., GARCIA, J., SANZ, M., \& CARRION, E

2007 Análisis de las estructuras, en El Bronce Medio y Final en la región de Madrid. El Poblado de la Fábrica de Ladrillos de Getafe. Estudios de Prehistoria y Arqueología Madrileñas 14-15, 29-68.

2004 Los poblados ribereños de hoyos en el entorno madrileño. Un modelo de asentamiento de la Edad del Bronce peninsular, en GARCÍA HUERTA, R. \& MORALES, J. La Península Ibérica en el II milenio a.C. Poblados y fortificaciones. Colección humanidades 77. 349-384. Universidad de Castilla - La Mancha. Ciudad Real.

2007a Cronología y consideraciones finales, en El Bronce Medio y Final en la región de Madrid. El Poblado de la Fábrica de Ladrillos de Getafe. Estudios de Prehistoria y Arqueología Madrileñas 14-15,193-206.

2007b El yacimiento y su entorno geográfico, en El Bronce Medio y Final en la región de Madrid. El Poblado de la Fábrica de Ladrillos de Getafe. Estudios de Prehistoria y Arqueología Madrileñas 14-15,13-28.

2012 Cogotas I en la Meseta española, en RODRÍGUEZ, J.A. \& FERNÁNDEZ MANZANO, J. Cogotas I. Una cultura de la Edad del Bronce en la Península Ibérica. 187-218. Universidad de Valladolid. Valladolid.

\section{BLASCO, C., CALLE, J. \& SANCHEZ-CAPILLA, M L.}

1991b Yacimiento del Bronce Final y de época romana en Perales del Río (Getafe, Madrid). Arqueología, Paleontología y Etnografía 1, 37-147.
BLASCO, C., LIESAU, C., RÍOS, P., BLANCO, J.F., ALIAGA, R., MORENO, E. \& DAZA, A.

2009 Kupferzeitliche Siedlungsbestattungen mit Glockenbecher und Prestigebeigaben aus dem Grabenwerk von El Camino de las Yeseras (San Fernando de Henares, Prov. Madrid). Untersuchungen zur Typologie des Grabritus und zu dessen sozialer Symbolik. Madrider Mitteilungen $50,40-70$.

BLASCO, C., SANCHEZ CAPILLA, M.L., CALLE, J., ROBLES, F., GONZALEZ, V.M. \& GONZALEZ, A.

1991a Enterramientos del Horizonte Protocogotas en el valle del Manzanares. Cuadernos de Prehistoria de la Universidad Autónoma de Madrid 18, 55-112.

1995 Fecha de C-14 de la Fase Protocogotas I del yacimiento del Caserío de Perales del Río. Cuadernos de Prehistoria de la Universidad Autónoma de Madrid 22, 83-99.

BRÜCK, J.

2006 Death, exchange and reproduction in the British Bronze Age. European Journal of Archaeology 9 (1), 73-101.

BUENO, P., DE BALBÍN, R. \& BARROSO, R.

2000 Valle de las Higueras (Huecas, Toledo, España). Una necrópolis Ciempozuelos con cuevas artificiales al interior de la Península. Estudos Prè- históricos VIII, 49-80.

\section{BUENO, P., BARROSO, R. \& DE BALBÍN, R.}

2005 Ritual campaniforme, ritual colectivo: la necrópolis de cuevas artificiales del Valle de las Higueras, Huecas, Toledo. Trabajos de Prehistoria, 62, 2, 67-90.

2008 Campaniforme en las construcciones hipogeas del megalitismo reciente al interior de la Península Ibérica. Veleia 24-25, 771-790.

2009 Agricultores y metalúrgicos en el valle de Huecas, en Arqueología, medio ambiente y obras públicas. El valle de Huecas (Huecas, Toledo). 35-71. Anthropos. Ciudad Real.

\section{CANTALAPIEDRA, V. \& ÍSMODES, A.}

2010 El yacimiento arqueológico de Aguas Vivas. Prehistoria reciente en el valle del río Henares (Guadalajara). Arqueología y Patrimonio vol.1. La Ergástula. Madrid.

\section{DELIBES, G. \& FERNANDEZ MIRANDA, M.}

1986-87 Aproximación a la cronología del grupo Cogotas I. Zephyrus XXXIX-X, 17-30.

\section{DÍAZ-DEL-RÍO ESPAÑOL, P.}

2001 La formación del paisaje agrario: Madrid en el III y II milenios BC. Arqueología, Paleontología y Etnografía 9. Comunidad de Madrid. Madrid.

DÍAZ DEL RÍO, P. \& VICENT, J.

2006 Movilidad, funcionalidad y usos del suelo en la Prehistoria Reciente. Arqueología Espacial 26, 21-36.

DUDAY, $\mathrm{H}$

2006 L' archéothanatologie ou l'archéologie de la mort (Archaeothanatology or Archaeology of Death), en Gowland, R. \& Knusel, C. Social archaeology of funerary remains. 30-56. Oxbow Books. Oxford. 
ESPARZA, A

1990 Sobre el ritual funerario de Cogotas I. Boletín del Seminario de Estudios de Arte y Arqueología LVI, 105-143.

ESPARZA, A., DELIBES, G., RAMOS, P., VELASCO, S. \& VELASCO, J.

2008 Una nueva sepultura del grupo Cogotas I en El Juncal (Villalralbo, Zamora). Zephyrus LXI, 155-175.

ESPARZA, A., VELASCO, J. \& DELIBES, G.

2012a HUM 2005-00139: Planteamiento y primeros resultados de un proyecto de investigación sobre la muerte en Cogotas I, en RODRÍGUEZ, J.A. \& FERNÁNDEZ MANZANO, J. Cogotas I. Una cultura de la Edad del Bronce en la Península Ibérica. 259-320. Universidad de Valladolid. Valladolid.

2012b Exposición de cadáveres en el yacimiento de Tordillos (Aldeaseca de la frontera, Salamanca). Perspectiva bioarqueológica y posibles implicaciones para el estudio del ritual funerario de Cogotas I. Zephyrus LXI, 95-128.

ESTACA, V. \& YRAVEDRA, J.

2011 Informe arqueozoológico del yacimiento de Yuncos. Inédito.

FABIAN, J.F. \& BLANCO, A

2011 El enterramiento en fosa del Cerro de la Cabeza (Ávila). La cuestión funeraria en el Bronce Final / Hierro I en el Suroeste de la Meseta Norte. Bibliotheca Praehistorica Hispana XXVIII, 183-194.

\section{FLORES, R.}

2011 El Yacimiento de Humanejos (Parla, Madrid), en BLASCO C., LIESAU, C. \& RÍOS, P. Yacimientos calcolíticos con campaniforme de la región de Madrid: nuevos estudios. 9-16. Patrimonio arqueológico de Madrid 6. Madrid.

GIL, J.I., MENENDEZ, M.L., REYES, F. \& REYES, J.L.

1988 Excavaciones en el yacimiento del Bronce medio del Cerro del Obispo Castillo de Bayela (Toledo). Congreso de Historia de Castilla - La Mancha T.III, 93-99.

\section{GÓMEZ, J. \& EXPÓSITO, A.}

2008a Memoria final de la excavación arqueológica del yacimiento El Espinillo. Proyecto U.Z.P. 2.04. Desarrollo del Este - Los Berrocales. Expte. 0650/05. MAR 2007/94.

2008b Memoria final de la excavación arqueológica del yacimiento La Capona. Proyecto U.Z.P. 2.04. Desarrollo del Este - Los Berrocales. Expte. 0650/05. MAR 2007/95.

\section{GONZÁLEZ MARTÍN, A.}

2008 Mitos y realidades en torno a la excavación, el tratamiento y el estudio de los restos arqueológicos no-adultos, en GUSI, F. MURIEL, S. \& OLARIA, C. Nasciturus, infans, puerulus vobis mater terra: la muerte en la infancia. 57-76. Servicio de Investigaciones Arqueológicas y prehistóricas. Diputación de Castellón.

INIESTA, J.

2006 Materiales Cogotas I procedentes del Caserío de Perales. Tesis Doctoral. Universidad Autónoma.

\section{LEDERMANN, S.}

1969 Nouvelles Tables-Types de Mortalité. Presses universitaires.Paris.

LIESAU, C., BLASCO, C., RIOS, P., VEGA, J., MENDUIÑA, R., BLANCO, J.F., BAENA, J., HERRERA, T., PETRI, A. \& GOMEZ, J.L.

2008 Un espacio compartido por vivos y muertos: El poblado calcolítico de fosos de Camino de las Yeseras (San Fernando de Henares, Madrid). Complutum 19 (1), 87-120.

\section{MACARRO, J.A.}

2002 La Alcalá prehistórica. El poblado de la edad del Bronce de "La Dehesa". Ayuntamiento de Alcalá de Henares. Alcalá de Henares.

\section{MEGÍAS, M. \& EXPÓSITO, A.}

2008 Memoria final de la excavación arqueológica del yacimiento Alto de las Peñuelas - Sector IV. Proyecto U.Z.P. 2.04. Desarrollo Este - Los Berrocales. Expte. 0650/05. MAR 2008/99.

MARINAS, E.

2013 El yacimiento de La Dehesa. Una aproximación al mundo funerario Protocogotas. Trabajo fin de Master. Universidad de Alcalá. Inédito

MARTÍN, A.

2006 Memoria de las excavaciones arqueológicas de urgencia del yacimiento de El Congosto (Rivas - Vaciamadrid Madrid) (Proyecto de ampliación de la Escuela Nacional de Protección Civil) I. Prehistoria Reciente. MAR 2004/06.

2010 Nuevos yacimientos en la comarca de La Sagra: asentamientos de la Edad del Bronce, Edad del Hierro y época romana de El Cerrón/ Casas de la Jerónima (Yuncos, Toledo). Actas de las II Jornadas de arqueología de Castilla - La Mancha. Castilla - La Mancha. Toledo Vol. 1, 192-216.

\section{MARTIN, P. \& MENDUIÑA, R.}

2003 Ficha de la parcela 14 del Polígono 25 (Alcalá de Henares, Madrid). Anuario de Actuaciones Arqueológicas y Paleontológicas 2002-2003. http://213.4.104.210/cgi-bin/ WebObjects/arqueologiaCAM.

\section{MARTÍNEZ NAVARRETE, M.I. \& MÉNDEZ, A.}

1983 Arenero de Soto. Yacimiento de fondos de cabaña del horizonte Cogotas I. Estudios de Prehistoria y Arqueología Madrileñas 2,183-254.

\section{MONTERO, J}

2011 Manifestaciones rituales e ideología durante la Edad de Bronce en el Interior Peninsular: la dimensión social de las prácticas funerarias de Cogotas. Tesis doctoral. Universidad de Burgos

\section{ORTIZ DEL CUETO, R. \& LOPEZ, L.}

1997 El yacimiento de la Edad del Bronce Príncipe 11: Ritual de inhumación infantil (Aranjuez, Madrid), Actas II Congreso de Arqueología Peninsular T. II, Fundación Rei Afonso Henriques. Zamora, 633-646. 
POLO, M.

2000 Indicadores paleonutricionales en restos óseos arqueológicos. Propuesta conceptual y metodológica. Trabajo de Investigación de Tercer Ciclo. U.D. Medicina Legal. Facultad de Medicina. Universitat de València. Inédito.

\section{PERERA, J., GARRIDO, G., PÉREZ, J. \& ROJAS, J.M.}

2010 La excavación arqueológica en el Yacimiento las Mayores en Numancia de la Sagra (Toledo). Campaniforme y Bronce en la Comarca de la Sagra. Actas de las II Jornadas de arqueología de Castilla - La Mancha. Castilla - La Mancha. Toledo. CD.

RAMOS, M.

2007 Cortecampo II (Los Arcos) y Osaleta (Lorca, Valle de Yerri). Sepulturas descubiertas en las obras de la Autovía del Camino, en La Tierra te sea leve. Arqueología de la muerte en Navarra. 93-96. Gobierno de Navarra. Pamplona.

RÍOS, P.

2011a Territorio y sociedad en la región de Madrid durante el III milenio a.C. El referente del yacimiento de Camino de las Yeseras. Patrimonio Arqueológico de Madrid 7. Universidad Autónoma de Madrid. Madrid.

2011b El yacimiento y su entorno geográfico, en ALIAGA, R. \& MEGÍAS, M. Los Berrocales (Madrid): un yacimiento de la Edad de Bronce en la confluencia Jarama-Henares. $\mathrm{Pa}$ trimonio Arqueológico de Madrid 8. 5-17. Universidad Autónoma de Madrid - Arqueomedia. Madrid.

ROJO, M. KUNST, M., GARRIDO, R., GARCIA, I. \& MORAN, G.

2008 Paisajes de la memoria: asentamientos del Neolítico antiguo en el valle de Ambrona (Soria, España). Instituto arqueológico alemán- Universidad de Valladolid. Valladolid.

RUIZ, F.

1975 Una necrópolis de la Edad del Bronce en Yuncos (Toledo). Sautuola 1, 117-133.

RUIZ, B., ANDRADE, A., DORADO, M., GIL, M.J., FRANCO, F., LOPEZ, P. LOPEZ, J.A., ARNANZ, A.M. \& UZQUIANO, P.

1997 Las transformaciones del ecosistema en la Comunidad de Madrid. Arqueología paleontología y etnografía 5. 95164. Consejería de Educación y Cultura de la Comunidad de Madrid.

SANABRIA, P.J., LÓPEZ, M., MORÍN, J., ESCOLÁ, M., FERNÁNDEZ, J., ILLÁN, J.M., LÓPEZ, G., NICOLÁS, E., SÁNCHEZ, F. SÁNCHEZ, M., YRAVEDRA, J. \& FERNÁNDEZ, C.

2007 Nuevos datos para el estudio de la Edad del Bronce en el Caserío de Perales del Río (Getafe, Madrid). Actas do IV Congresso de arqueología peninsular. As Idades do Bronze e do Ferro na Península Ibérica. (Faro - 2004). Universidade do Algarve 09. Faro, 227-238.

\section{SÁNCHEZ POLO, A.}

2012 Algo más que animales de compañía: la deposición ritualizada de perros en hoyos en el solar de Cogotas I, en RODRÍGUEZ, J.A. \& FERNÁNDEZ MANZANO, J. Cogotas I. Una cultura de la Edad del Bronce en la Península Ibérica. 449-468. Universidad de Valladolid. Valladolid,
TRANCHO, G.J., ROBLEDO, B. y LOPEZ-BUEIS, I.

2004 Análisis Paleonutricional, en A. JIMENO, I. DE LA TORRE, R. BERZOSA \& J.P. MARTINEZ La necrópolis Celtibérica de Numancia. Arqueología en Castilla y León 12, 434-451.

UBELAKER, DH.

1978 Human skeletal remains. Washington: Taraxacum.

URGÉ, J. \& RUIZ PEDRAZA, S.

2004 Memoria informe de la intervención arqueológica: Red de suministros POS.22 ERAR BUTARQUE (Perales del Río, Madrid). Inédito. MAR 2002/66.

\section{VALIENTE, J.}

1992 La Loma del Lomo II. Cogolludo (Guadalajara). Patrimonio Histórico - Arqueología. Castilla - La Mancha.

VEGA, R.

2009 Propuesta de protocolo y laboratorio de campo en osteoarqueología: aplicación a los yacimientos de la Edad de Bronce de "El Espinillo" y "Alto de las Peñuelas - Sector IV" (Vallecas, Madrid). Trabajo de Investigación. Laboratorio de Poblaciones del Pasado, Universidad Autónoma de Madrid.

VICENT, J.

1995 Problemas teóricos de la arqueología de la muerte. Una introducción, en FÁBREGAS, R., PÉREZ, F. \& FERNÁNDEZ, C. Arqueoloxía da Morte na Península Ibérica desde as Orixes ata o Medievo. 13-31. Concello de Xinzo de Limia. Xinzo de Limia.

\section{VIRSEDA, L. \& DOMINGUEZ, R.M}

2008 Memoria de la intervención arqueológica en el yacimiento de Pista de Motos (Expte. 718-05). Vol. I. Trabajos realizados. MAR 2006/7.

VIRTAMA, P., KIVILUOTO, R., PALKAMA, A. \& TELKKÄ A.

1962 Estimation of stature from radiographs of long bones in children. Children ages from ten to fifteen. Annales Medicinae Experimentalis Biologiae Fenniae 40, 283-285

\section{YRAVEDRA, J. y ESTACA, V.}

2013 Anejo VII. Informe arqueozoológico, en MORíN, J. Rasero de Luján. Las producciones cerámicas en el territorio segobricense. MArq. Audema. Serie época romana/ Antigüedad tardía, 171- 174 